NBER WORKING PAPER SERIES

\title{
WHAT EXPLAINS DIFFERENCES IN FINANCE RESEARCH PRODUCTIVITY DURING THE PANDEMIC?
}

\author{
Brad M. Barber \\ Wei Jiang \\ Adair Morse \\ Manju Puri \\ Heather Tookes \\ Ingrid M. Werner \\ Working Paper 28493 \\ http://www.nber.org/papers/w28493 \\ NATIONAL BUREAU OF ECONOMIC RESEARCH \\ 1050 Massachusetts Avenue \\ Cambridge, MA 02138 \\ February 2021
}

We are very grateful to Annette Clark, the Executive Committee of the American Finance Association (AFA), and in particular AFA President Ken Singleton for his guidance and encouragement throughout this project. We would like to thank Cam Harvey, Jennifer Koski, and participants at the 2021 AFFECT reception for helpful comments. The views expressed herein are those of the authors and do not necessarily reflect the views of the National Bureau of Economic Research.

NBER working papers are circulated for discussion and comment purposes. They have not been peer-reviewed or been subject to the review by the NBER Board of Directors that accompanies official NBER publications.

(C) 2021 by Brad M. Barber, Wei Jiang, Adair Morse, Manju Puri, Heather Tookes, and Ingrid M. Werner. All rights reserved. Short sections of text, not to exceed two paragraphs, may be quoted without explicit permission provided that full credit, including $\$ notice, is given to the source. 
What Explains Differences in Finance Research Productivity During the Pandemic?

Brad M. Barber, Wei Jiang, Adair Morse, Manju Puri, Heather Tookes, and Ingrid M. Werner NBER Working Paper No. 28493

February 2021

JEL No. G0,G01

\begin{abstract}
$\underline{\text { ABSTRACT }}$
Using a survey of AFA members, we analyze how demographics, time allocation, production mechanisms, and institutional factors affect research production during the pandemic. Consistent with the literature, research productivity falls more for women and faculty with young children. Independently and novel, extra time spent teaching (much more likely for women) negatively affects research productivity. Also novel are the results that concerns about feedback, isolation, and health have large negative research effects, disproportionately affecting junior faculty and $\mathrm{PhD}$ students. Finally, faculty facing greater concerns about employers' finances report larger negative research effects and more concerns about feedback, isolation and health.
\end{abstract}

\begin{tabular}{|c|c|}
\hline Brad M. Barber & Manju Puri \\
\hline Graduate School of Management & Fuqua School of Business \\
\hline One Shields Avenue & Duke University \\
\hline 3218 Gallagher Hall & 100 Fuqua Drive \\
\hline University of California & Durham, NC 27708-0120 \\
\hline Davis, CA 95616 & and NBER \\
\hline bmbarber@ucdavis.edu & mpuri@duke.edu \\
\hline Wei Jiang & Heather Tookes \\
\hline Graduate School of Business & Yale School of Management \\
\hline Columbia University & New Haven, CT 06520-8200 \\
\hline 3022 Broadway, Uris Hall 803 & heather.tookes@yale.edu \\
\hline New York, NY 10027 & \\
\hline and NBER & Ingrid M. Werner \\
\hline wj2006@columbia.edu & $\begin{array}{l}\text { Fisher College of Business } \\
\text { Ohio State University }\end{array}$ \\
\hline Adair Morse & 2100 Neil Avenue \\
\hline University of California, Berkeley & Columbus, OH 43210 \\
\hline 545 Student Services Bldg, \#1900 & werner.47@osu.edu \\
\hline $\begin{array}{l}\text { Berkeley, CA } 94720 \\
\text { and NBER }\end{array}$ & \\
\hline
\end{tabular}

An online appendix is available at http://www.nber.org/data-appendix/w28493 


\section{Introduction}

The COVID-19 pandemic has rapidly upended modern life, tested the infrastructure of higher education globally, and pushed professors and administrators to their productive limits. While there is now hope that effective vaccines will bring an end to the current state of chaos, there still may be long-term consequences for higher education. In this paper, we explore three main channels that might disparately affect the research productivity of faculty (and Ph.D. students) and hence their long-term career outcomes, which are primarily dependent on successful research records. First, we consider disruptions to time allocations since the pandemic resulted in sharp disruptions in time allocations and these disruptions are significantly associated with faculty characteristics such as seniority, gender and family structure. Second, we consider production mechanisms that affect research productivity beyond time allocation like the inability to obtain feedback, concerns about isolation, or concerns about physical or mental health. These production mechanisms likely affect productivity per unit of time input and thus can contribute to reductions in research independent of time allocations. We expect these mechanisms to vary with faculty characteristics like seniority, gender and family structure. Finally, we consider institutional factors, such as the perceived financial condition of the institution and tenure clock extension policies, and examine their impact on research productivity. To preview our results, we find all three factors (time, production, and institutional mechanisms) play an important role in explaining variation in the effect of the pandemic on research productivity. Our results raise concerns that the pandemic will have long-lasting and disparate impact on, and thus shift the representation of, various groups in the faculty population.

Our study builds exclusively on data from a voluntary survey that we sent to the membership of the American Finance Association (AFA) on October 26, 2020. We asked members to evaluate the impact of the pandemic on their own research productivity and on the time spent on research and related activities. Because individuals with university-related positions comprise $85.4 \%$ of the 1,440 responses, we focus the analysis solely on this group. Most of the survey responses are reported in Likert scales (from 1 to 5), which is accommodated by the ordered logistic models. The empirical approach allows us to examine the impact of predetermined variables (gender and family structure), rank (senior, junior, student), and mechanisms (time, production, and institutional factors), holding other things constant and allows for formal analyses of potentially important interactions. Because the pandemic hit everyone by complete surprise, and because the regressors in our models represent mostly pre-existing characteristics, endogeneity should not be a major concern in interpreting the regression results.

During the pandemic, most faculty report a negative effect on research, but importantly for our analysis there is considerable variation in this effect. While $78.1 \%$ of faculty respondents report decreases in research productivity and $60 \%$ report spending less time on research, there are also $14.5 \%$ of faculty who report increases in research productivity and $21.5 \%$ report spending more time on research. The variation 
in research effects relates to predetermined factors - family structure and gender. Research productivity of women and faculty with children, especially very young ones (ages 0 to 5), is particularly harmed by the pandemic, and the two factors seem to work independently without a significant interaction effect. That is, presence of young children affects research production during the pandemic by similar degree for men and for women, but women are still more negatively impacted for given family structure. The career and professional implications of these effects are important. Women, in particular senior women, are already an underrepresented group within the academic finance profession, and thus achievements attributed to efforts to ameliorate the disparity in recent years could see a set-back post-pandemic. Also set back are junior faculty of both genders, as they are more likely to have young children and experience professional isolation. Junior faculty are the group for whom current research productivity will have the greatest impact on future career outcomes. Thus, on both counts, the impact of the magnitudes of distortions may have profound effects on research and on the profession as a whole.

We then turn the main question we address in this paper: What mechanisms generate disparate effects on research productivity? The pandemic and the resulting lockdowns and social distancing requirements greatly affected how academics spend their time. Faculty need to devote more time to teaching, as they work to adopt entirely new models of remote and hybrid teaching. Faculty with children may spend more of their time navigating school and day care closures or they may have increased responsibilities when their adult children return home. To shed light on the time allocation mechanisms driving the negative research effects, we asked respondents to report the changes in time allocation to tasks other than research. The time allocation questions are particularly telling, given the hard budget constraint of 24 hours a day. As expected, we find that faculty with children spend more time on childcare and domestic chores while cutting back on time spent on research, leisure, and sleep. In contrast, time spent on teaching is unaffected by the presence of children, because teaching is a task with fixed deadlines which requires immediate attention.

What is less expected is our finding that women spend more time teaching and less time on research after controlling for family structure. While increased time spent on teaching should be expected for all faculty given the rapid transition to online instruction, the fact that women report a bigger increase in their teaching burden than men unfortunately further exacerbates the gender gap in research productivity. Given the substantial evidence of bias against women (especially junior women) in teaching evaluations (e.g., Rivera and Tilcsk, 2019; Mengel, Sauermann, and Zolitz, 2019), the pressure to gain favorable teaching ratings - an important component in tenure and promotion considerations - may elicit more effort from women, compared to men, on teaching at the expense of time for research (e.g., Winslow, 2010). Moreover, female professors tend to experience more demands and special requests from students as students continue to perceive and expect female professors to be more nurturing than male professors (El-Alayli, HensenBrown, and Ceynar, 2018). The pandemic, and ensuing major transition of mode of teaching, only 
exacerbated this gap, an important finding that has not be discovered in other survey and research. Importantly, gender differences in the increased time spent teaching do not explain the gender effect that we are observe in research productivity. In contrast, the productivity loss due to children is completely explained by time being allocated to childcare, chores, and teaching, rather than potential unobserved heterogeneity between faculty with and without children.

Having sketched out the effects of the pandemic on time allocation, we then study the effect of these time mechanisms on research productivity. Time spent on teaching, childcare, and chores are all important determinants of research productivity. Of the potential time allocation mechanisms that we identify, time spent on childcare and chores have a particularly strong compromising effect on research. These two variables predictably and reassuringly absorb the effects of the predetermined family structure variables (but not gender).

In addition to the directional effects, the economic magnitude of these effects is equally interesting, which prompt us to extract marginal effects from the estimated ordered logistic models. The magnitude of effects of childcare and chores turn out to be enormous. Holding all other covariates constant at sample means senior (junior) faculty who report spending "much more" time on childcare are 54.7 (47.2) percentage points (ppts) more likely to report "much less," or the most significant negative effect on research productivity. Though this finding is consistent with the mounting evidence from other fields that young children are associated with significant reductions in productivity (e.g., Krukowski, 2020; Myers et al., 2020; Deryungina et al. 2021), the magnitude we uncover is staggering. Moreover, these marginal effects still understate the total expected effects on junior faculty because they are also more likely to have young children then senior faculty, as $37.7 \%$ of junior faculty report spending "much more" time on childcare versus $29.4 \%$ of senior faculty. We multiply the probability of exposure to the pandemic-related childcare burden by the marginal effects of the burden on research productivity to obtain what we call the “expected effect" for a member of the group. A junior faculty member has a 17.8 percentage point increased probability of reporting the most extreme negative research outcome as a result of "much more" time spent on childcare (47.2 percentage point marginal effect times the $37.7 \%$ probability of reporting "much more" childcare). In comparison, the expected effect of childcare on research productivity for senior faculty is 16.1 percentage points, less than that for junior faculty due to lower exposure to a childcare burden.

The marginal effect of teaching on research productivity is smaller, but still sizable. For example, senior and junior faculty who report spending "much more" time on childcare are 39.0 and 26.5 percentage points, respectively, more likely to report "much less," the most significant negative effect on research productivity. Senior faculty are slightly more likely than junior faculty to report spending "much more" time on teaching (23.6\% versus $19.8 \%$ ) and, as a result, the expected effect of a severe teaching burden is much larger for senior faculty than junior faculty (9.2 versus 5.2 percentage points). 
While time diverted from research is a major cause for drop in research productivity, the pandemic effect could manifest itself in other ways. Professional conferences and traditional opportunities to disseminate research and obtain feedback may no longer be feasible or may not be as effective in remote formats. Like the general public, faculty may feel isolated or overwhelmed by concerns about their own health and well-being. These mechanisms likely affect productivity even for fixed units of work time, and thus can contribute to reductions in productivity independent of time allocations. As a result, we refer to these mechanisms as production mechanisms.

To capture the effect of production mechanisms on research productivity, we study wellbeing (concerns about physical and mental health) and two characteristics essential to the development process of research - feedback and, its opposite, isolation. Specifically, we ask faculty whether they have concerns about lack of feedback on research, worries about isolation, or worries about their physical or mental health with all responses recorded on a 5-point Likert scale (with " 3 " being no concerns; and a higher value indicates a more concerning condition).

After controlling for time allocations, these production mechanisms (concerns about feedback, isolation, and health) indeed have independent negative effects on research productivity. The economic magnitudes of these effects rival those of the time allocation variables and also vary by rank. For example, senior and junior faculty who report "much more" concern about feedback are 49.9 and 41.7 percentage points, respectively, more likely to report the most significant negative effect on research productivity. Though the marginal effect looks similar between the two groups, junior faculty are much more likely than senior faculty to have the highest concern about lack of feedback (38.9\% versus $22.6 \%$ ). Hence, the expected effect of the highest feedback concerns on junior faculty is more than $40 \%$ greater than that of senior faculty (16.2 versus 11.3 percentage points). The marginal effects of health concerns on research outcomes are also large, but somewhat less than those related to feedback concerns (46.9 and 30.3 percentage points for senior and junior faculty, respectively). Again, because junior faculty are much more likely than senior faculty to have these concerns (30.7\% versus $15.2 \%)$, the expected effect gap is larger for junior rather than senior faculty (9.3 ppts versus 7.1 percentage points). The marginal effects of isolation concerns are analogous to those associated with feedback and health concerns. There is already broad evidence that mental health affects employment prospects and workplace productivity (Bubonya et al. 2017; Frijters et al. 2014) and that the associated costs are large in magnitude (Greenberg et al. 2015). However, we are the first (to our knowledge) to report direct links between research productivity in academia to pandemic-related increases in concerns about isolation and mental health.

When we examine students separately from faculty, we discover that factors affecting students are different. While students report a negative research effect, it is less dramatic than that reported by junior faculty, and the time students spend on research has not changed as dramatically. For students, the time 
mechanisms (teaching, childcare, and chores) remain important, but the marginal effects are small relative to faculty. Moreover, students are less likely than faculty to report the most extreme time burdens from teaching, childcare, or chores. As a result, the expected effects on students are less than $4 \%$ for all three time variables.

But the pandemic imposes a unique toll on the students mentally, as they are reporting greater concerns about isolation and health than faculty. Like faculty, these wellbeing and social connective factors negatively affect the research productivity of students independent of the time allocations. The marginal effects of the most extreme concerns on the probability of a student reporting the most negative research productivity impact are $23.4,25.0$, and 33.7 percentage points for isolation, health, and feedback, respectively. But $41.9 \%$ of students express the most extreme concerns about health and $32.8 \%$ express the most extreme concern about isolation. (Interestingly, they are less likely to report concerns about feedback perhaps because students either have advisors who continue to provide feedback or lack a finished research product at the stage for external feedback.) While we do not ask about overall mental health (we combine physical and mental health and then separately ask about feelings of isolation), our findings are consistent with mounting evidence of significant mental health challenges during the pandemic. For example, Chirikov, Soria, Horgos, and Jone-White (2020), both report that, between May and July 2020, 39\% of graduate students screened positive for anxiety and 32\% screened positive for depression. These are increases from $26 \%$ and $15 \%$ (respectively) from $2019 .{ }^{1}$ To be sure, graduate students (and faculty) are privileged in that they are generally able to enjoy intellectual freedom and work flexibility that can afford a healthier work-life balance in normal times compared to those in other professions. However, the survey reveals that, like the general population, those in the academic life are vulnerable to isolation and concerns about health as a result of COVID-19, especially those earliest in the career trajectory. Moreover, we find direct links between these factors and declines in research productivity.

Finally, we turn to factors driving variation in research production coming from institutional factors. We find that the negative research effects are larger for faculty employed by institutions with more serious financial concerns, because teaching becomes more demanding as universities struggle to retain students and support for research wanes with budgetary cuts and hiring freezes. We also find evidence that faculty who are more concerned about the financial health of their employers express greater concerns about lack of feedback, social isolation, and health.

\footnotetext{
${ }^{1}$ These data are in line with National Center for Health Statistics survey evidence that the proportion of young adults (18-29 years old) reporting symptoms of depression has doubled from 2019 to December 2020 (https://www.cdc.gov/nchs/products/databriefs/db379.htm). In April 2020, three months into the global COVID-19 crisis, the percentage rose to $32.7 \%$ and reached $43.6 \%$ in December of 2020 (https://www.cdc.gov/nchs/covid19/pulse/mental-health.htm).
} 
Institutions responded with a variety of pandemic-related policies, from which we focus on tenure clock extensions, intended to compensate for loss of research time and access to data or lab, and additional time required to adapt to new teaching models. The extension is also part of the effort to address career concerns and to support the mental health of untenured faculty. Unfortunately, our finding suggests that such a onesized policy has unintended consequences. Junior faculty employed by institutions that have extended the tenure clock report decreased research productivity, presumably due to a relaxation of the deadline imposed by tenure review. More importantly, clock extensions may have unintended consequences to exacerbate the dispersion of productivity within cohorts, rendering junior faculty who are most negatively impacted by the pandemic in an even more disadvantageous position at tenure review which usually deploys comparison within cohorts. Such an effect is analogous to what Antecol, Beddard, and Stearns (2018) document as the unintended consequence of the gender-neutral policy on parental leave. Finally, these policies do not appear to help alleviate pandemic-related stress: junior faculty at institutions with tenure clock extensions are no less likely to report feelings of isolation, reduced ability to receive timely feedback, or overall health concerns. We hope that our findings could raise awareness among institutions to expand coverage of mental health support during this time and to provide clearer guidance on mental health issues.

Our study contributes to multiple strands of literature and have direct policy implications. First and foremost, we contribute to a quickly emerging new field the examines the impact of the pandemic on life and productivity of academics, usually via survey methods. We echo some of the recent evidence that women and women with children in the STEM fields (including economics) were particularly affected by COVID-19 (e.g., Cui et al., 2020; Deryugina et al., 2020; Myers et al., 2020). In STEM, Frederickson (2020), Sugimoto (2020), and Andersen (2020) all report significant declines in research by female authors relative to men since the onset of the pandemic. Amano-Patino et al. (2020) report that women economists are vastly underrepresented in the new and flourishing area of COVID research. We also reconcile with Kruger, Maturana, and Nickerson (2020)'s finding that though the overall volume of working papers increased during the pandemic there has been a gender gap in the posting of papers online. Although evidence on the disparate impact of the pandemic on research for women and faculty with young children is growing, we still know little about the underlying mechanisms driving these differences, which is the focus of our study.

An important incremental contribution of this study, relative to the existent survey-based research, lies in our examination of three potential channels that might contribute to research productivity changes: time allocation, physical and mental health concerns (production mechanisms), and institution-level effects. We delve into not just the effect of gender and children, but we also ask how these pre-determined family structure variables relate to time allocation decisions during the pandemic. The approach is in the spirit of Myers et al. (2020) but we examine changes in time allocated to a richer set of activities (including 
childcare, chores, leisure and sleep) to help us understand the mechanisms driving changes in time allocated to research. The time allocation measures that we examine are similar to contemporaneous work by Deryungina et al. (2021); however, Deryungina et al. (2021) do not study the relationship between time allocation and changes in research productivity (the main variable of interest in this paper). And, unlike both Myers et al. (2020) and Deryungina et al. (2021), we examine respondents' concerns about their own physical or mental health, isolation, and ability to obtain timely feedback on their work; these factors likely hinder the exchange of ideas and feedback that is crucial to the production of impactful research. Thus, we explore a rich set of potential drivers of changes in research productivity during the pandemic. Third, we study the effect of the university's financial condition and decision to extend tenure clocks on research productivity outcomes.

We also enrich this new field by exploring variations across professional ranks. Our data include large samples of senior faculty, junior faculty and Ph.D. students, allowing us to understand and uncover novel evidence in the differential effects of time mechanisms (e.g., teaching, childcare, and chores), production mechanisms (e.g., concerns about feedback, health, isolation) and highlight potentially important implications for junior scholars and students, who will shape the profession for years to come.

The disparate effects of COVID-19 that we document have implications that extend beyond finance academia and beyond the specific setting of COVID. Many of the professional responsibilities of finance faculty and the research criteria by which they are evaluated are shared across a wide range of disciplines. And lessons learnt from COVID are applicable to other major negative shocks to academic production that might happen in the future. If administrators are not deliberate in their policy responses to the pandemic, the sharp decline in research productivity reported by faculty with children and female faculty will have lasting impacts on careers and the diversity of individuals contributing to knowledge production. In particular we caution against one-size-fits-all policies such as a uniform tenure clock extension, echoing the earlier findings of Anecol et al. (2018) on gender-neutral parental leaves in a new setting, and providing empirical support for the sentiment expressed in the opinion piece by Malisch et al. (2020). Our findings support policy responses accounting for the disparate impact of a common negative shock (Oleschuk, 2020), e.g., via an opt-out tenure clock extension, more support to junior faculty, and non-essential service relief.

\section{Data}

\subsection{Survey Overview}

We designed the survey with two goals: (i) to collect a large sample that is less likely to be affected by selection and (ii) to obtain a statistically powerful observation count to allow us to explore not only the effect of COVID on individual researchers but also the underlying mechanisms. Toward that aim, we 
designed a short survey (less than 5 minutes) with no tracking of locations or information that could reveal location so as to reduce potential concerns from respondents. The American Finance Association (AFA) kindly agreed to implement the survey.

After obtaining requisite IRB clearances and signing data use agreements, we sent an invitation to take the voluntary survey to 8,421 members of the AFA via email on October 26, 2020, with a deadline of November 4, 2020. Two reminders were sent out, on October 31 and on November 4, 2020. A total of 1,440 responses were received by the deadline, for a response rate of $17.5 \%$ after accounting for bounced email (see Online Appendix for details). ${ }^{3}$

Given the importance of research productivity to institutions and to individual career outcomes, the key information we solicited regarded how research productivity and time allocated to research were affected by the pandemic. We also asked questions about changes in research support, specifically financial resources and feedback from colleagues. The survey was anonymous, and we did not collect IPs or other identifiers; however, we collected demographic information on gender, professional role, tenure status (for faculty), household structure (spouse/partner, children), and continent location. The surveyed individuals were also asked about their institution's response to the pandemic such as extensions of tenure-clocks and elimination/optionality of student evaluations of instruction. Finally, we asked how concerned survey respondents were about a number of emerging issues related to the pandemic, such as isolation, online teaching, in-person teaching, children's' education, employer and personal finances, and personal health. The survey questions are summarized in the Online Appendix.

\subsection{Descriptive Statistics}

Unless otherwise stated, we use all survey respondents as the denominator (regardless of whether they answered a specific question). The respondents are distributed across geographic regions as follows: $51.9 \%$ of the respondent work in the U.S.; 24.6\% in the European Economic Area (EEA); and 23.4\% in the Rest of the World (RoW). Respondents with university-related positions comprise $85.4 \%$ of the sample and this is the subsample which our main analysis focuses on. Among respondents who identify as male or female, $66.8 \%$ identify as male and $33.2 \%$ female. $^{4}$

In the main analyses, we focus on the respondents with university-related positions who identified themselves as male or female. We delete an additional 42 observations where all responses to time allocations are blank or all responses to concerns/worries are blank. The resulting main sample consists of 1,008 university respondents: 731 faculty (402 senior faculty and 329 junior faculty) and 277 students. The

\footnotetext{
${ }^{2}$ A copy of the invitation is in the Online Appendix.

${ }^{3}$ Typical response rates for voluntary surveys without incentives (such as gift cards, etc.) ranges from $10-20 \%$ in recent years (Pedersen and Nielsen (2016)).

${ }^{4} 226$ individuals, or $15.7 \%$, chose "prefer not to answer", "other", or do not answer the question about gender identity.
} 
geographic representation of the final sample is very similar to that of all respondents (55\% US, $25 \%$ EEA, $20 \%$ RoW).

This sample selection is driven by the objectives of the study, the relatively low number of responses from non-university researchers, and heterogeneity in their career demands. Non-university researchers face different trade-offs than faculty, as they typically do not teach. They also do not have a tenure-track process. We do not consider the group without disclosed gender information since their responses would not allow us to uncover potential disparate effects on female researchers.

Table 1 reports the summary statistics for our sample, and the subsamples of senior faculty, junior faculty, and Ph.D. students. The average response to the question "How did the COVID-19 pandemic affect your research productivity?" (Research_Productivity) is 1.94 for faculty, based on a Likert scale from $1=$ significantly negative to $5=$ significantly positive (where 3 is the neutral value). Junior faculty are the most negatively affected group. Both senior faculty and students report less of a negative effect than junior faculty (a difference of $0.35, t=4.06$, and $0.38, t=4.29$, respectively).

[Insert Table 1 here.]

The decline in self-reported research productivity that we observe seems more negative compared to findings in concurrent research by Kruger, Maturana, and Nickerson (2020), who report a 35\% increase in new finance and economics working papers posted to SSRN following the pandemic. ${ }^{5}$ There are several potential explanations for why the average survey respondent reports adverse effects on research productivity while working paper postings increased. First, while many scholars are reporting decreases in productivity, not all of them do. Indeed, $14.5 \%$ of our sample reports that the pandemic has had a "slightly positive" or "very positive" impact on their research productivity. COVID-19 has steepened the productivity curve, where more productive researchers may become even more productive. Second, COVID-19 itself acts a natural experiment for many settings and has attracted a lot of research. Such research has more urgency than usual and might push researchers to post on SSRN (and other open-source repositories) in an earlier stage. Third, outside of such "topical" research, SSRN postings might capture a part of the research process that has suffered less from the crisis (e.g., later stage work on revisions or very new projects). This would be expected if the time required to prepare an initial draft of already up-andrunning project is less than the investment one makes when starting something new or revising existing work for publication. Finally, it could also be that survey respondents are those who are most negatively affected by the pandemic as it is generally true that subjects that are expected to be more affected by policies

\footnotetext{
${ }^{5}$ Similarly, Cui, Ding, and Zhu (2020) report a similar increase for social science researchers more generally. They report that total research productivity increased by $35 \%$, in terms of open-access preprint repositories, ten weeks after the lockdown in the U.S.; however, female researchers' productivity dropped by $13.9 \%$ relative to that of male researchers. Within their sample, they report that increases in gender differences were particularly large in Finance (along with Criminal, Economics, Health Economics, Political Science, and Sustainability).
} 
coming out of the survey are more likely to participate (Bertrand and Duflo, 2016). Importantly, even if this is the case, it would not drive the cross-sectional variation (i.e., role of family structure, seniority and gender) that we observe in the data.

The variable that captures changes in time spent on specific activities (Time_Activity) is based on a Likert scale from $1=$ much less time to $5=$ much more time during compared to before the pandemic. The stay-at-home measures to help curb the spread of COVID-19 thrust faculty into rapid transitions to online teaching. At the same time, many faculty took on at-home tasks such as childcare, home schooling, and domestic chores part of which may have been outsourced under normal circumstances. This forced researchers to reallocate their time significantly. Faculty in our sample report spending significantly less time on research, leisure, and sleep while spending more time on teaching, childcare/schooling, and household chores than before the pandemic. The effects of COVID-19 on time allocation are similar for senior and junior faculty (none of the differences between the two groups are statistically significant). In contrast to faculty, however, Ph.D. students do not report a significant decline in time allocated to research or teaching; they even sleep more during the pandemic. Compared to faculty, students also report a smaller increase in time devoted to childcare and schooling and a smaller decline in leisure, mostly due to the fact that Ph.D. students are significantly less likely to have children.

Thirty percent of the faculty respondents in our final sample are female (fem_ind). This fraction is higher among junior faculty (33.4\%) and is even higher among students (45.5\%) than among senior faculty (27.1\%). The lower representation of women among the most senior faculty is consistent with the faculty population in economics and related fields. For example, Committee on the Status of Women in the Economics Profession's (CSWEP) 2019 reports that women comprise: 14.6\% of full professors; 25.9\% of associate professors; $30.3 \%$ of assistant professors; and 32.3\% of graduating Ph.D. students. The percent female finance faculty respondents to our survey are larger than some of the estimates that appear in the current literature and suggests greater response rates from women. ${ }^{6}$ Over-sampling women should not impact the estimated gender effects if the males and females who do respond do not have pandemic-period experiences that differ, along gender lines, from those who do not.

Family structure is a variable of interest in any analysis of how the COVID-19 pandemic affects researchers. The need to spend additional time on childcare and schooling as well as on domestic chores is likely to depend on the size of the household, age of the dependents, and whether or not those tasks can be shared with partners. We gather several variables to capture all these aspects of household characteristics. In light of evidence from other fields that presence of young children reduces productivity (e.g., Krukowski,

\footnotetext{
${ }^{6}$ Sherman and Tookes (2020) report that women comprise $16 \%$ of their sample of female faculty at top 100 business schools. Chari and Goldsmith-Pinkham (2018) report 14.6\% female representation on the finance programs at the NBER Summer Institute.
} 
2020; Myers et al. 2020), we focus the analysis on the ages of children (if any) and whether a respondent has a non-working spouse or partner (nonwork_spouse). On average $24.9 \%$ of our faculty respondents have a non-working spouse, and senior faculty are more likely to have a non-working spouse than either junior faculty or students.

In terms of children, $62.4 \%$ of senior faculty and $55.3 \%$ of junior faculty have children between the ages of 0 and 18 , while only $19.9 \%$ of students have children. The age distribution of children varies predictably for senior and junior faculty. Among all respondents, $32.6 \%$ have children between the ages of 0 to 5 years, and another $30.2 \%$ have children in the 6-12 year category. Junior faculty tend to have younger children than senior faculty. To facilitate interpretation of our results, we construct a cardinal variable, between 0 and 3, to summarize the ages of children (childcardinal), corresponding to the level of required parental care. It constructed as follows: 0 for no children or children 18 and over; 1 for children ages 1318; 2 for children ages 6-12; and 3 for children ages 0-5.

The pandemic has caused many people to shelter at home, which has reduced the ability of faculty to interact, both professionally and socially. This lack of social connection affects the ability of faculty to receive feedback on their work, can create the feeling of social isolation, and induce worry about one's physical or mental health. All such factors might affect research productivity. We construct three variables to measure these dimensions of the pandemic experience: Feedback, Isolation and Health.

We ask survey participants about the impact of COVID-19 on a researcher's ability to receive timely feedback (Feedback) on their research projects, working papers, or other work. We again use a Likert scale from $1=$ strong positive impact to $5=$ strong negative impact so that a higher value corresponds to a more negative outcome. ${ }^{7}$ The average reports a negative impact on the ability to receive timely feedback, and it is particularly junior faculty that feel they do not get timely feedback during the pandemic (a difference of 0.33 compared to senior faculty, $t=5.26)$. Students appear somewhat better off than junior faculty in terms of getting timely feedback (a difference of $0.36, t=4.97$ ), perhaps because students do not yet require external research feedback as much and they have supervisors in place to provide feedback.

We also ask respondents about their well-being in the wake of COVID-19. For this study, we focus on two concerns: isolation due to working from home (Isolation) and physical and mental health (Health). These variables are reported on a Likert scale where $1=$ strongly disagree and $5=$ strongly agree, that is, a higher value corresponds to a more negative outcome. We find widespread self-reported worry among faculty and students about isolation and health. The means for all groups are significantly above the neutral value of 3. Comparing senior and junior faculty, we find that junior faculty worry more about isolation and health than their senior colleagues (differences of $0.23, t=2.75$, and $0.45, t=5.53$, respectively). Students

\footnotetext{
${ }^{7}$ For ease of interpretation, this variable is rescaled so that an answer of a "strong positive" impact is assigned a 1 and a "strong negative" impact a 5 .
} 
and junior faculty have similar concerns about isolation, but students reveal even greater concerns about physical and mental health (a differences of $0.26, t=3.30$ ). This finding is consistent with Woolsen (2020), who reports a doubling of signs of depression among graduate students during the pandemic based on a survey at nine leading research universities in the U.S.

Apart from personal characteristics, university policies and institutional resilience also impact faculty members' personal experiences. To investigate institutional effects, we focus on two variables: ExtendClock and Employer_Finances. The ExtendClock variable is based on responses to a number of questions about how institutional policy has changed in response to the COVID-19 pandemic. For ease of interpretation, we define the dummy variable (ExtendClock) to be one if the institution either gave the option to extend the tenure clock or automatically extended the tenure clock, and zero if no such policy is in place. On average $68.9 \%$ of faculty respondents say their institutions have policies that enable junior faculty to extend the tenure clock.

Similar to the worry about isolation or physical/mental health, we ask respondents if they are worried about their employer's finances ( $1=$ strongly disagree and $5=$ strongly agree), hence a higher value corresponds to a less ideal state. We use the response to this question to identify institutions that are likely more affected financially by the pandemic. The basic idea is that variation in responses to this question can capture variation in the financial resilience of universities to the crisis (e.g., endowment fluctuations, exposure to international students, etc.). Faculty report some worry about employer finances. While the mean worry for senior faculty is slightly larger in magnitude than for the other groups, the average value of the variable Employer_Finances is not statistically different across senior faculty, junior faculty, and students.

\subsection{Family Structure by Gender and Rank}

A burgeoning literature (e.g., Schiebinger et al., 2008; Minello, 2020) on the impact of COVID-19 on working professionals has naturally identified the role played by family structure. Most importantly, the pandemic kept children home who would otherwise be in school or daycare during most working hours. To set the stage for more analytical empirical testing, Table 2 shows descriptive statistics on the key family structure variables, by rank and gender.

\section{[Insert Table 2 here.]}

Among faculty, women are significantly (at the 1\% level) less likely to have a nonworking spouse than men (14.2\% vs. $29.5 \%)$. The difference is also increasing with seniority: from $9.9 \%$ among Ph.D. students to $16.1 \%$ among senior faculty. The gap is significant across all ranks and is consistent with survey evidence in Schiebinger et al. (2008), who report that male academics are more likely to have stay-at-home partner than women. Senior women are somewhat more likely to have children that are between the ages of 0 and 
18 , but the difference is only statistically significant for children between the ages of 6 and 12. In contrast, junior women are much less likely to have children at all age groups except children over 13 . Note that children at this age range were likely born prior to the commencement of the academic career (or even before entering the Ph.D. program). The fact that senior women are significantly more likely than men to have young children and junior women are less likely to have children confirms the documented delaying childbirth among female scholars (e.g., Mason and Goulden (2002); Armenti, 2004; Antecol et al., 2018). There are no notable differences among Ph.D. students.

\section{Empirical Results}

\subsection{Allocation of Time}

COVID-19 had disrupted normal life and forced to change ways people allocate their time. To characterize the effect on researchers, we ask respondents to report changes in their time allocation preversus post- the start of the pandemic across six categories of activities. We then analyze how the changes in time allocation vary with gender and family structure. The six categories included in our analysis are time spent on: research (Time_Research), teaching (Time_Teaching), domestic chores (Time_Chores), caring for children (Time_Childcare), leisure activities (Time_Leisure), and sleep (Time_Sleep).

Allocation of time inherently reflects trade-offs and hence time spent in each of the six categories (which are the dependent variables in the regressions) represent a joint decision made for time spent in the others. For this reason, we adopt the seemingly unrelated equation system model so that all six equations representing the six categories are jointly estimated in that the error disturbances in the equations are allowed to be correlated in arbitrary ways. Moreover, because the dependent variables are coded on Likert scale from 1 to 5 (where a higher number indicates more time spent compared to a normal time), we use an ordered logistic model in all equations so that the dependent variable can be viewed as interval-coded (from 1 to 5), condensed from a latent underlying variable that is continuous. The independent variables are the pre-determined family structure and gender variables. The full equation system is as follows for $i=1,2,3$, 4, 5, 6 where $i$ is the index for categories:

$$
\begin{gathered}
\text { Time }_{i}=a_{i}+\beta_{1 i} \text { female }+\beta_{2 i} \text { nonwork_spouse }+\beta_{3 i} \text { childcardinal } \\
+\beta_{4 i}(\text { female } * \text { childcardinal })+e_{i}
\end{gathered}
$$

The coefficients in equation (1) are "log odds ratios" in an ordered logit model and carry a subscript $i$, as they are equation specific. In addition to equation (1), we also explored the role of the interaction of fem_ind with nonwork_spouse and the triple interaction of the explanatory variables. These extra interactions did not have sufficient power to identify statistically significant time allocation patterns here or the research patterns in subsequent tables; thus, we omitted them and resort to the parsimonious model with variables that are most central to our interest. Table 3 reports the results. 


\section{[Insert Table 3 here.]}

The qualitative interpretation of the coefficients in Table 3 is similar to a linear regression model in that a positive (negative) coefficient suggests a correlation in the same sign between the covariate and the dependent variable, holding other covariates constant. The same is true for interpretation of the statistical significance.

Table 3 shows striking gender effects in how the pandemic has changed researchers' time allocation. The estimated coefficients on fem_ind implies that women allocate significantly (at the 5\% level) less time to research, and significantly (at the $1 \%$ level) more time to teaching following the onset of the pandemic. The magnitudes of these two coefficients are comparable, and changes in time allocated to all other categories exhibit little disparity along the gender dimension. A non-working spouse/partner (nonwork_spouse), as expected, decreases time allocated in childcare (significant at the $10 \%$ level), but most of the time saved seems to go into teaching (significant at the $10 \%$ level). On balance, and somewhat surprisingly, the research time advantage of researchers with a non-working spouse is insignificant.

The presence of children in the family, especially young children (childcardinal), significantly (at the $1 \%$ level) increases time spent on childcare and domestic chores. The extra time has to be diverted from other activities, resulting in reduced allocation in research, sleep, and leisure activities (in that order). All of these negative effects are significant at the $1 \%$ level. The coefficients on the interaction term fem_ind $\times$ childcardinal indicate that presence of children, especially young ones, has an incremental impact on female researchers such that they spend even more time on childcare and even less time on leisure activities than their male counterparts. Both effects are significant at the 5\% level. The estimated coefficient on the fem_ind $\times$ childcardinal interaction term in the Time_Research regression is insignificant, implying that women with children strived to maintain roughly the same research time compared to men with similar family structure.

The quantitative magnitudes of the coefficients in an ordered logit model are not as straightforward as that in a linear regression. Here the coefficients are "log odds ratios," and therefore, the coefficients exponentiated become the odds ratio. Take the coefficient of -0.420 on fem ind in the equation for Time_Research as an example. Suppose the probability that a researcher responds that time allocated to research has changed in a particular way, such as "much less time" (i.e., level 1 out of 5$)$ is $(1-p)$. Then the odds ratio for the researcher to end up in any level higher than the current one is $p /(1-p)$. The value of the coefficient suggests that, if the gender of the researcher is changed from male to female while keeping other variables constant, the odds ratio that the researcher could go to a higher level is reduced by $34.3 \%$ $(\exp (-0.42)=0.657$; given the neutral value being one, this is $34.3 \%$ below the reference level $) .{ }^{8}$

\footnotetext{
${ }^{8}$ The ordered logit model assumes that the sensitivity of the odds ratio of going to higher level(s), from any given level below the top level, has constant elasticity with respect to the covariates. The model does allow differential base-
} 
A more intuitive way to present the gender disparity result in Table 3 from the ordered logit model is to show the predicted probabilities of a subject to end up in each of five levels (from "much less time" to "much more time") separately for men and women, assuming that they both have the same family structure imputed with the sample average values of nonwork_spouse and childcardinal. Figure 1, which contains six subfigures, compares the predicted probabilities that an average woman and an average man would respond in one of the five levels of time allocation for each of the six time categories (with other covariates measured at sample averages). For Time_Research (top left subfigure), women lead men in reporting "much less" (24.3\% vs. $18.5 \%)$ and "less" (41.7\% vs. $39.3 \%)$ time spent in research compared to pre-pandemic levels, and trail men in all three higher levels. As for time spent in teaching (top middle subfigure), women are less likely to report the three lowest levels $(1.0 \%, 6.2 \%$, and $26.6 \%$ for "much less," "less," and "about the same" respectively) than men $(1.4 \%, 8.6 \%$, and $32.2 \%)$, and more likely to be in the "more" and "much more" levels. For domestic chores (top right subfigure), very few men and women report less work than before, but women are less likely to remain "about the same" than men (33.2\% vs. $36.8 \%)$ and are correspondingly more represented in the two higher levels. A very similar pattern applies to time allocated to childcare (bottom left subfigure). For leisure activities (bottom middle subfigure), proportionally more women report "much less" than men (37.3\% vs. 32.8\%). Finally, the bottom right subfigure shows that proportionally fewer women report that they have kept the same amount of sleep time $(57.1 \% \mathrm{vs} .59 .3 \%)$, with the difference mostly offset by the "less time" category.

[Insert Figure 1 here.]

We apply the same method to show the predicted probabilities being in any of the five reported time allocation categories, where we sort researchers in increasing order of demands for childcare using the presence of children and their ages: No child at home; children 13-18 years; children 6-12 years, and children 0-5 years. It is clear from Figure 2, top left subfigure, that the probabilities or answering "much less time" allocated to research increases monotonically with the demand of childcare: $10.9 \% \%, 17.8 \%$, $28.1 \%$, and $41.1 \%$. The pattern for the "less time" category is similar but less steep. The three higher-level categories all show a reverse order. For example, predicted probabilities for reporting "more time" in research are $26.2 \%, 17.8 \%, 11.1 \%$, and $6.6 \%$. The steepest contrast in this sorting, not surprisingly, occurs in time allocation to childcare (bottom left subfigure). The predicted probabilities of being in the "much more time" categories are $2.8 \%, 14.4 \%, 49.8 \%$, and $85.3 \%$ from no-child to at least one child being in the 0-5 year age range. A similar, but less steep, pattern prevails in time spent in domestic chores and reverse patterns are observed in time spent in leisure and sleep. Interestingly, there is very little difference in time

level probabilities for each level, which are captured by the intercept estimates associated with different levels. This is analogous to a linear model, except that the linear relation pertains to the $\log$ odds ratio. 
spent teaching as we vary childcare demands. More likely this could reflect that time required for teaching is less flexible than research time and has to be put in regardless of other constraints; indeed the pandemic with the move to online classes may have imposed a uniform learning time cost on all.

[Insert Figure 2 here.]

We would like to note that the ultimate effects of a non-working spouse and children on men versus women is more nuanced than what the regressions and corresponding figures indicate. This is because the coefficients represent estimates conditional on a particular state, but they ignore the differential unconditional probabilities of being in the state for men and women. The summary statistics in Table 2 show that non-working spouse is much more common for men, while junior women are less likely to have children. Hence, the total impact of COVID-19 will vary accordingly even if the coefficients on these variables are similar across different groups.

\subsection{Research Productivity}

The time allocation changes reported in Table 3 capture tradeoffs for the scarce resource of time. Research time is a pre-requisite for research output but is also just one of many inputs into research productivity. To understand how the pandemic is affecting research productivity as an output, we turn to our output measure of self-assessed research productivity. We first look at how research productivity varies according to predetermined variables, gender and family structure. We then add time inputs (of time spent on non-research activities), which reflect how people are allocating time differently during the pandemic. We then layer in variables that measure concerns regarding social interactions and health, which may also affect people differentially. Mental health is of particular concern, given that there is already broad evidence that mental health affects employment prospects and workplace productivity (Bubonya et al. 2017; Frijters et al. 2014) and that the associated costs are large in magnitude (Greenberg et al. 2015). Our analysis provides the first (to our knowledge) glimpse at potential linkages between research productivity in academia to pandemic-related increases in concerns about isolation and mental health.

We begin by estimating an ordered logistic regression analogous to the time allocation estimations of Table 3, but the dependent variable is now the effect of the pandemic on research productivity, ranging from 1 (strong negative effect) to 5 (strong positive effect). Results are reported in Table 4. In Table 5, we run the same regressions as in Table 4, but we separate the subjects into three groups according to seniority: senior (i.e., tenured) scholars, junior scholars, and Ph.D. students. This allows us to examine potentially differential impacts of COVID-19 at different stages of research career.

$$
\text { [Insert Table } 4 \& 5 \text { here.] }
$$

Column (1) of Table 4, and Columns (1), (3), and (5) of Table 5 include as regressors only exogenous factors, including the gender and family structure variables. Table 4 Column (1) shows that having a non- 
working spouse helps research productivity (at the 10\% significance level). The breakdown of subjects into three groups based on seniority rank (Table 5) reveals that the non-working spouse effect is driven by junior faculty, not tenured faculty nor by Ph.D. students. Young children negatively impacted research productivity during the pandemic for all faculty; the effect is highly significant (at the 1\% level) for senior and junior faculty, but not at all significant for $\mathrm{Ph} . \mathrm{D}$. students. Even after controlling for family structure, however, women are still significantly (at the 1\% level) more negatively impacted by COVID-19. Moreover, the magnitude of the gender effect increases as faculty become more senior, it goes from small and insignificant for Ph.D. students, to sizable and marginally significant (at the $10 \%$ level) for junior faculty, to large and highly significant (at the 1\% level) for senior faculty.

We can think of two possible explanations for the gender disparity in research productivity even after controlling for family structure. First, senior women generally take on disproportionately more service work for both their employers and the profession due to their under-representation. For example, Guarino and Borden (2017) document that women, especially senior women, shoulder disproportionately more service work such as serving on committees and mentoring students. The volume of such work ballooned during the pandemic as most schools set up many task forces to address the challenges created by the pandemic. As such, female scholars, especially senior women, in the profession may have faced disproportionately more administrative "taxes" on their research productivity. Second, the impact of childcare transmits via the coauthor network. A researcher's productivity could be negatively impacted if their coauthors are time-constrained due to the heightened childcare needs. Table 3 shows that women spend more time in childcare than men even given the same family structure, which induces a larger indirect effect on women as a whole (including those without young children of themselves) because women, on average, three times more likely to have female coauthors than men (Sarsons, et al. (2020))

Similar to Figures 1 and 2, Figure 3 presents the predicted probabilities of changes in research productivity based on the model of Table 4, column (1). The results echo those of the time allocation graphs summarized in Figures 1 and 2. In Figure 3, the left subfigure shows a sizable gender gap in the predicted reporting of "much less" research productivity, 53.9\% for women and $43.0 \%$ for men. The right subfigure shows the impact of children. Consistent with the patterns in Figure 2, the impact of children is the steepest in the "much less" category. The predicted probability for a researcher to feel "much less" productivity than before is $31.8 \%$ for those without children at home, $42.7 \%$ with children of age $13-18$ years, $55.4 \%$ with children of age 6 to 12; and $67.4 \%$ with children of age 0 to 5 . An equally steep distribution also manifests itself in the predicted probabilities that researchers will report "more" or "much more" productivity range from $5.8 \%$ for faculty with children ages 0 to 5 to $21.6 \%$ for faculty with no children. This highlights the positive productivity shocks for a segment of the faculty population, who could be contributing to the increased flow of papers posting in the repositories or submitted to journals during the pandemic. 
[Insert Figure 3 here.]

In Columns (2) and (3) of Table 4, we further explore potential mechanisms underlying the relationship between research productivity and both gender and family structure, including the role played by the time inputs. For this analysis, we step in the time allocation variables to assess their effect on the predetermined family structure and gender variables. Columns (2) shows that the negative effect on research that is associated with having young children is completely explained by time allocated to childcare and chores. Column (3) shows an additional negative effect on research associated with time devoted to teaching. These effects all significantly hurt research productivity (at the $1 \%$ level).

In the last column of Table 4, we add three new variables that characterize the professional environment and social-psychological state of faculty. Feedback, Isolation, and Health measure concern about timely feedback on research, isolation, and physical/mental health on a Likert scale ranging from "Not Concerned" (value of one) to "Very Concerned" (value of five). Column (4) of Table 4 shows that perceived lack of feedback on research and concerns for health are highly significantly (at the $1 \%$ level) correlated with research productivity; and the feeling of isolation also contributes negatively (significant at the 10\% level) to research productivity.

Returning to Table 5, the breakdown by seniority rank further reveals that the time consumed by childcare affects junior scholars more than seniors (both are significant at the $1 \%$ level), but it does not significantly impact Ph.D. students (who are also less likely to have children). The impact of time allocated to teaching affects faculty, but not Ph.D. students (perhaps because their teaching is limited or confined to supporting roles). Domestic chores affect all groups roughly evenly. Lack of feedback on research and concern for personal health also affects self-reported research productivity of all groups similarly, but perceived isolation hit the Ph.D. students the hardest. Students are the only group with a significant effect of isolation, which is consistent with the increased rates of depression and anxiety among graduate students reported in Woolston (2020).

Several interactive effects are worth noting. First, comparing the different specifications in Tables 4 and 5 sheds light on whether and to what extent time choices absorb the effect of family structure. The time choices only slightly offset the effect from a nonworking spouse. However, the inclusion of changes in time allocated to childcare, chores and teaching render the coefficients on childcardinal insignificant, both economically and statistically, and for all groups of subjects. Such an absorption implies that the variable childcardinal, in this context, is not picking up heterogeneity between households with and without children outside of the parental time commitment required to childcare during a time when the usual help (day care, babysitters, housekeepers etc.) were not available. The contrast between the baseline and extended regressions in Tables 4 and 5 suggests that the impact of family structure on research productivity during 
the COVID-19 pandemic was more likely to be causal than being the outcome of unobserved heterogeneity across households that are correlated with children.

Second, the coefficient on the interaction term fem_ind $\times$ childcardinal is positive and significant (at the $1 \%$ level) when time allocation is controlled for (Table 4, Columns 3 and 4 ). This is true for the faculty subsample (Table 5, Columns 2 and 4), but not Ph.D. students (Table 5, Column 6). Moreover, the inclusion of the interaction term does not notably change the magnitude of the coefficients of fem_ind. Therefore, women seem to be more effective at offsetting the loss of research time due to time spent with children in a more research-productive way than men. This is a novel finding and is consistent with the idea that women may have already learned, more than men, how to adapt to multitasking and managing work-life balance.

Finally, the inclusion of social psychological variables reduces the gender effect: The coefficient on fem_ind changes from -0.718 to -0.514 from columns (3) to (4) in Table 4, suggesting that part of the gender disparity might be driven by differential impact of COVID-19 on the environment and psychology of women and men. The next section will explore this mechanism in more detail.

\subsection{Intensity of Mechanisms that Affected Research Productivity}

Building on the previous results, this section further explores the various mechanisms that reduce research productivity, and how such mechanisms vary with gender and seniority rank. More specifically, we estimate a regression of the following form:

$$
\text { Mech }_{i}=a+\beta_{1} \text { junior }+\beta_{2} \text { female }+\beta_{3}(\text { junior } * \text { female })+e_{i} .
$$

In equation (2), the dependent variable, Mech, is a group of variables representing potential mechanisms through which COVID-19 impacts research productivity. The mechanisms that we consider include concerns about feedback, isolation, and physical/mental health (Feedback, Isolation, and Health). We also include the family structure variables, nonworking_spouse and childcardinal. The independent variables include gender, seniority ranks (dummy variables for junior faculty and students), and the interaction of the two. We highlight junior faculty and Ph.D. students because their long-term career outcomes are potentially more vulnerable to the pandemic shock. In these regressions, senior faculty serves as the omitted category. Table 6 reports the results.

\section{[Insert Table 6 here.]}

In Table 6, all of the odd columns report regressions results for the faculty subsample only; all the even columns include both faculty and Ph.D. students. Overall, the results in Table 6 show that junior faculty are in a significantly weaker position to withstand the COVID-19 shock compared to senior faculty: They are more likely to express concerns for the lack of feedback on their research, to feel isolated, and to worry about their own health (physical or mental). The last four columns examine the distribution of pre-existing family structure in relation to junior and student status. Results confirm that junior scholars and Ph.D. 
students are less likely to have the help of a non-working spouse and are more like to have young children (compared to the omitted category of senior scholars). All of these factors, significant at the $5 \%$ level or less, have a negative effect on research productivity, contributing to the overall lower research productivity reported by juniors in Table 1. In sum, despite the fact that the elasticity at which mechanisms affecting productivity impact junior and senior faculty is similar (Table 5, Columns 2, 4 and 6), the intensity of the mechanisms is consistently greater for junior faculty.

Focusing on gender, we find that women are also more concerned about feedback than their male peers (significant at the $1 \%$ level) possibly due to the relatively narrow professional network and the relative scarcity of other senior female scholars in the field. ${ }^{9}$ The network issue was only exacerbated during the COVID-19 pandemic, as conferences and seminars went virtual and other opportunities to interact with colleagues were dramatically reduced. While women express similar feelings of increased isolation relative to men, they expressed more concerns over their own health (significant at the 5\% level) than men. They are also less likely to have a nonworking spouse though the presence of children does not differ significantly. In short, the mechanisms affecting research productivity tend to be more intense for women than men.

Several interaction terms reveal additional nuances. For example, the reliably negative interaction of junior $\times$ female in the Feedback regression (Columns 1 and 2) indicates that concerns regarding feedback are similar for male and female junior faculty (which are significantly higher than for senior faculty), but they are significantly stronger for senior women compared to senior men. Analogously, the reliably negative coefficient on junior $\times$ female interaction term in the regression where childcardinal is the dependent variable (Column 9) suggests that junior men are more likely than junior women to have high childcare needs (consistent with Table 2, which shows that junior women are less likely than junior men to have children).

Table 6 then extends the analyses to include students. Though students do not express increased concerns about feedback (perhaps because many are not at the stage to have a product requiring feedback beyond the supervisors), they do report significantly heightened concerns about isolation (at the 5\% level) and health (at the 10\% level) compared to faculty. Due to the stage in their lives in which many students attend graduate school, students are less likely to have a nonworking spouse and are less likely to have children. Connecting results in Table 6 with those in Table 5, we learn that Ph.D. students are not only more likely to feel isolated and are concerned about their health, but also that a given level of such a state exerts a stronger effect on their research productivity. The coefficients of the interaction between female and

\footnotetext{
${ }^{9}$ Sherman and Tookes (2020) report that women represent only $14.8 \%$ of tenured faculty in 2017 , and their sample of recent graduates is $20.4 \%$ female. Santos and Phu (2019) document a similar pattern among 24 Russell Group universities in the UK.
} 
student in Table 6 all point to a negative impact on research productivity, though only the effect on health is significant (at the 5\% level). In other words, female Ph.D. students are significantly more likely to be concerned about their own health compared to their male classmates. The combined results from the student subsample demand more awareness by institutions and the profession on the physical and social conditions on the next-generation of scholars in a negative shock like the COVID-19 lockdowns.

\subsection{Marginal and Expected Impact of Mechanisms that Affect Research Productivity Across Professional Ranks}

Table 5 shows that time allocation, feedback, isolation, and health mechanisms all contribute to the average decline in research productivity for faculty and $\mathrm{PhD}$ students alike. The economic magnitudes of these effects, in addition to the directional signs, are of considerable interest. To calibrate the economic significance, we calculate how a particular mechanism affects the probability that a researcher ends up in the state of being "much less" research productive, the most negative impact category. We focus on two categories of mechanisms - time mechanisms and production mechanisms. For the mechanism of "time spent on childcare," for example, we are interested in how researchers who have an input value of 5 ("much more" time spent on childcare) fare, relative to those who have an input value of 3 ("no change" in time spent on childcare), in terms of being "much less" research productive. We estimate this effect as a marginal effect in ordered logit estimation, setting all other variables at their respective mean values. There are analogous calculations for all the other variables. We depict these marginal effects in Figure 4.

In Figure 4, Panel A, the marginal effects of time spent on teaching, childcare and chores are all large. For example, senior faculty spending "much more" time on childcare, relative to "no change," are 54.7 percentage points more likely to be in the state of "much less" research productive. The childcare effect is somewhat less for junior faculty and dramatically lower for students. We observe a similar pattern for time spent on chores across ranks, and those who are devoting "much more" time to chores are again over 50 percentage points more likely to be "much less" research productive. These effects of work-life balances on research output during this unusual time, even temporary, could have long-lasting impact on career outcomes and competitive positioning among demographics.

The other balances that researchers have to make are the work-work balance, say, allocating time between teaching versus research. In Figure 4, Panel A, we depict the marginal effects of time spent on teaching on the probability of reporting being "much less" research productive. Senior faculty who spend "much more" time teaching (relative to "no change") experience a 39.0 percentage point higher probability of being "much less" research productive. This effect is a third lower for junior faculty, perhaps reflecting their pressure to perform in research, and/or the extra burdens senior faculty experience in teaching as they are more likely to teach multiple subjects and in leading the curriculum. 
We turn to the other production mechanisms - wellbeing and social connection variables - in Figure 4, Panel B. These mechanisms likely affect productivity per unit of time and thus can contribute to reductions in research independent of time allocations. The figure shows effects that rival those of the time allocation variables; note that the figures are on the same y-axis scale. Senior faculty, junior faculty, and students expressing the most significant worries about feedback are 49.9 percentage points, 41.7 percentage points, and 33.7 percentage points more likely to report being "much less" research productive. All of these magnitudes are large. Feedback is clearly a critical input in our research production process. The lack of feedback may be from local colleagues (especially, perhaps for students and juniors), but also the lack of conversations at in-person conferences and seminars is clearly taking a toll on our profession's ability to exchange ideas and provide feedback. Even the mergence of seminars and conferences on Zoom does not fully restore spontaneous interactions and serendipitous brainstorming, and such a shortfall may be particularly hard on scholars who yet to establish themselves in the profession.

Isolation has the smallest effect and varies relatively little by rank, but we nevertheless want to draw attention to the effect of isolation on students. Students who are "much more" worried about isolation are 23.4 percentage points more likely to be "much less" research productive. Finally, we turn to physical and mental health. Health concern has a dramatic effect on research productivity. Seniors who are much more worried about health are 46.9 percentage points more likely to be "much less" research productive. This effect drops to 30.3 percentage points and 25.0 percentage points for students, presumably younger people are physically more robust in general. However, many of us have heard stories of how many Ph.D. students are struggling with mental as well as physical health during the pandemic.

We would like to note that the marginal effects across different groups do not take into account that the groups exhibit disparity in being in a category (say, "much more" worried about health). This leads us to analyze not just the marginal impact of each mechanism, but the expected total impact for anyone in a given rank within the population. Put differently, the marginal effects shown in Figure 4 summarize the impact for a given change in a particular mechanism by rank, but do not account for the differential probability that the mechanism is in place across ranks. Although time spent on childcare has a bigger effect on senior faculty, junior faculty are more likely to have small children in the home. Thus, the expected effect of childcare on junior faculty could still be greater because of their greater likelihood of having children in the first place. To make more pertinent comparisons of the relative magnitudes of the effects that account for both the marginal effect and the exposure of a particular group to the mechanism, we plot the expected marginal effect on research productivity in each population by multiplying the marginal effects shown in Figure 4 by the probability that each group reports "much more" (i.e., a value of 5) for the input of interest. We summarize the results in Figure 5. 
In Figure 5, Panel A, we summarize the time variables. In stark contrast to the marginal effects, we observe that junior faculty are more likely to endure a negative effect from childcare and chores. For example, a junior faculty member is 17.8 percentage points more likely to report a significant negative research impact that can be traced to a significant increase in childcare responsibilities despite the fact that the marginal effect of both variables is smaller on junior than senior faculty. This result obtains because

junior faculty are more likely to report significant increases in time spent on childcare because of the stage in the life cycle they are in. In contrast, the expected marginal effects on students are quite small because they are less likely to have significant increases in childcare and chores during the pandemic and the marginal effects of these demands are also smaller.

In Figure 5, Panel B, we summarize the wellbeing and social connection variables. These patterns are also starkly different from those reported in Figure 4, Panel B. Junior faculty are much more likely to be affected by the lack of feedback than senior faculty or students. The expected increase in the probability that a representative junior faculty is "much less" research productive because of being "much more" worried about feedback is 16.2 percentage points. The effect on students is now materially lower than junior faculty, because students are less likely to be in the category of having the highest worry about feedback. This emphasis on feedback for juniors in particular reflects, perhaps, the setting where students' advisors still look after students advanced in their dissertation work, but juniors lack such a built-in feedback process.

In contrast, worries about both isolation and health have larger expected impacts for the student population than for faculty. This magnitude is important in many ways. We find that any student is 10.5 percentage points more likely to be "much less" research productive because of being "much more" worried about physical and mental health. The effect is also large for juniors. This finding suggests that ten percent of students (and a little less so for junior faculty) are suffering severe research production declines because of mental and physical health concerns.

Bringing some of these findings together, we find that junior faculty are most affected by the lack of feedback and childcare burdens. Students are most affected by concerns about feedback, isolation and health. Institutions' efforts to support their faculty and Ph.D. student populations need to account for the heterogeneous ways in which the crisis has taken a toll on research.

\section{Institutional Variation and Responses}

In this section, we explore variation in the effect of COVID-19 on research productivity across institutions. We focus on differences in financial strength and the tenure accommodation policies introduced as a result of the pandemic. 


\subsection{Institution Financial Strength}

Research requires resources which are impacted by the institutional financial situation. Not only do universities differ hugely in terms of their endowments, revenues, and gifts, but they were also affected by the COVID-19 shock differently. For example, schools relying more heavily on tuition from international students are hit harder (Fischer, 2019). We attempt to capture faculty members' assessments of their institutions' financial health by using the responses to a question about employer finances. Specifically, we use responses to "I worry about the finances of my employer," where responses measured on a 5-point Likert scale from 1 to 5.

To quantify the impact of employer finances on employee research productivity, we estimate an ordered logistic regression where the dependent variable is Research_Productivity. We also estimate regressions where the dependent variable is a factor that affects research output and likely varies across institutions (Time_Research, Time_Teaching, Feedback, Isolation, and Health). The key independent variable is Employer_Finance, the self-reported concern for employer finances from "strongly disagree" (value of one) to "strongly agree" (value of five), where a lower value indicates a better financial situation. All variables are in the original 5-point scale.

\section{[Insert Table 7 here.]}

Table 7 reports the results. We find that heightened concern about employer finances and vulnerability to the COVID-19 shock is significantly (at the 1\% level) associated with lower research productivity. In the remaining columns of Table 7, we also observe all of the mechanisms that affect research productivity are stronger at institutions that are perceived as financially insecure. Heightened concern about employer finances is associated with less time spent in research, more time spent in teaching (as teaching became incrementally more demanding in schools with poor financial cushions), more worries about feedback on research, more intense feeling of isolation, and more concerns about own health.

Figure 6 is analogous to Figures 1 through 3 and shows the relationship between worry about employer financial health and changes in research productivity and time spent on teaching (the two most important job activities of faculty), using the same method to predict probabilities as in the earlier figures. The left subfigure shows that the predicted probability in the "much less" research productivity category increases monotonically and steeply with the worry for the financial conditions of their institutions $(30.0 \%, 35.8 \%$, $43.2 \%, 50.9 \%$, and $58.6 \%$ from "strongly disagree" to "strongly agree," respectively). The patterns in all higher levels of research productivity manifest a reverse order, but the steepest ascendances are in the "more" and "much more" research productivity categories.

\section{[Insert Figure 4 here.]}

One mechanism driving the impact of institutional financial well-being on research productivity could be teaching. Universities with financial constraints may be imposing more teaching burdens on faculty. 
These burdens could be in the form of more preparations, more course loads, and/or inadequate support for faculty to transition to online teaching. As a result, faculty at less well-endowed institutions and institutions that experience more revenue drops lose more research productivity due to more time spent on teaching, a relation existed before the pandemic (O’Meara et al., 2003; Hanlon, 2019). The right subfigure of Figure 4 confirms this hypothesis. It shows that the predicted probability that subjects spend "much less," "less," and "about the same" time in teaching is monotonically decreasing in their worry for employer financial condition; and the order is reversed for the predicted probability that subjects spend "more" or "much more" time in teaching. For subjects that "strongly disagree" that they worry about employer finance, the predicted probability that they have to spend "much more" time in teaching is $12.1 \%$, the same figure is more than doubled at $29.4 \%$ for subjects that "strongly agree" with the statement regarding worry about their employer.

Overall, COVID-19, already a negative shock, has the unfortunate additional impact of exacerbating the existing unequal resources and support for researchers due to variation in the financial conditions of their universities. We anticipate the gap in research productivity between researchers in well-endowed institutions and those in the less resourceful schools will increase in the coming years.

\subsection{Clock Extensions}

One prompt policy response to the pandemic was the decision by many universities to extend the tenure clock, either automatically or optionally. This action acknowledged the fact that research would suffer considerable delays due to direct forces such as limited or suspended access to labs and data, and indirect ones such as hiring freezes on research assistants. To explore the effect of these clock extensions on research productivity, we construct an indicator variable, ExtendClock, that equals one if the respondent affirms the presence of an automatic or optional clock extension for untenured faculty at their institution. About 70\% of respondents indicate the presence of such a policy (see Table 1). The clock extension policy may also be a proxy for an institution's overall willingness and preparedness to support employees during an unusually difficult time. In this analysis, we restrict the analysis to junior faculty since it is among this group that we would expect to observe changing behavior in response to tenure clock changes. Results are reported in Panel B of Table 7.

Interestingly, clock extension, if anything, reduces research productivity (significant at $10 \%$ ), and also reduces time allocated to research (not significant) and teaching (significant at 10\%). While it is plausible that junior faculty reduce research in response to a clock extension because they no longer feel an impending deadline, we find it surprising that we observe a similar effect for teaching. None of the remaining mechanisms are affected by the clock extensions in a statistically significant way. 
We emphasize that clock extension policies are one-size-fits-all and temporary accommodations. Clock extensions do not address the differential mechanisms that are affecting productivity (e.g., variation in teaching responsibilities, family structure, and gender). Given that different groups are differentially impacted by the pandemic as we report here, sweeping clock extension policies may exacerbate rather than address disparities that have emerged during the crisis. The outcome could well be analogous to the unintended consequence of the gender-neutral parental clock-stopping which ended up creating a new advantage for men relative to women, as analyzed in Antecol, Bedard, and Stearns (2018). This is because men on average are able to allocate more time into research than women during parental leaves, but a "cohort" analysis (that is, comparing researchers with about the same length of time since $\mathrm{Ph} . \mathrm{D}$. degree) at tenure evaluation remains a convention.

In our context, $14.5 \%$ of the faculty respondents to our survey responded that their research productivity increased during the pandemic, and this outcome is significantly correlated with gender and family structure. This subset of researchers is given more time to accelerate relative to others under the policy. In institutions giving the same length of clock extension within the sample of clock-extending institutions, those whose research productivity is more negatively impacted by COVID-19 due to pre-existing situations are expected to lag behind. And, given the cohort comparison method commonly adopted in the tenure review process, male faculty and faculty without young children may catapult above the rest as a result of with the additional time given due to the current public health crisis. The outcome may well be a repeat of the parental-leave effect, aka Antecol, Bedard, and Stearns (2018), where a non-differentiating policy led to a discriminatory outcome. In their call for new solutions to support equity in academia, Malisch et al. (2020) encourage institutions to develop strategic action plans to account for differential changes in faculty productivity due to COVID-19. Our survey results support the need for such action plans. We encourage discussions on how to incorporate the differential effects of the pandemic on individual faculty research, based on objective information such as the presence of young children. Such guidance will be particularly important for letter writers, who are often asked for a cohort comparison when assessing a candidate's merit for tenure.

Our findings on faculty and student concerns around physical and mental health and isolation should also be considered. At many institutions, faculty are being encouraged to discuss the effect of COVID-19 on their research productivity in merit or promotion reviews. These practices may not address potential mental health issues that affect research productivity because the stigma associated with mental illness may cause people to underreport mental illness compared to other health conditions (Bharadwaj, Pai, and Suziedelyte 2017). Even if promotion candidates do report on these conditions, it is possible that some reviewers will not consider mental illness a consideration on par with other health conditions absent explicit 
institutional guidance on the issue. At a minimum, we recommend explicit institutional guidance and statements on best practices.

\section{Conclusion}

COVID-19 has upended normal life and dramatically changed the working environment for most researchers. To understand the impact of COVID-19 on research productivity in the academic finance profession, we administered a survey to the membership of the American Finance Association (AFA).

In the survey, we asked members to evaluate the impact of the pandemic on their own research productivity and on the time spent on research and related activities. Overall, faculty respondents report a negative research effect. But there is also heterogeneity in the response, with $14.5 \%$ of our faculty respondents reporting an increase in research productivity. We analyze how effects on research productivity differ by seniority, gender and family structure.

We find that there is a significant overall decline in research productivity but there are marked differences by family structure and gender. In particular, research productivity of women and faculty with young children are affected more adversely. Further, while faculty are spending more time on their teaching, we observe a strong gender effect, with women reporting spending more time on teaching-related activities. Our results suggest that the pandemic has the effect of widening the gap for women and for faculty with young children.

We further examine the underlying mechanism for differentials in research productivity by examining changes in time allocation of different tasks. Here we find that the productivity loss of faculty with young children stems from time being allocated to childcare and chores.

Our survey results suggest that, like the general population, faculty and students are also vulnerable to isolation and concerns about health as a result of COVID-19. We directly relate these concerns to research productivity. We find that perceived lack of feedback on research, concerns for health, and feelings of isolation are highly correlated with reduced research productivity. These concerns are particularly strong for junior faculty, and for faculty in institutions with serious financial concerns. Ph.D. students are particularly vulnerable to feelings of isolation.

Many institutions have responded to the pandemic with blanket uniform extensions of the tenure clock for junior faculty. Our results suggests that there are heterogeneous effects of the pandemic with systematic patterns for different groups. As such, one size fits all clock extension policies may exacerbate rather than address disparities that have emerged during the crisis. We hope that the findings reported here generate discussion and awareness among university administrations about the potentially disparate impact of a wellintentioned uniform policy. 


\section{References}

Amano-Patiño, Noriko, 2020, Who is doing new research in the time of COVID-19? Not the female, VOX, CEPR Policy Portal.

Andersen, Jens Peter, Mathias Wullum Nielsen, Nicole L Simone, Resa E Lewiss, and Reshma Jagsi, 2020, COVID-19 medical papers have fewer women first authors than expected, eLife 9.

Anon., 2020, How Will the Pandemic Change Higher Education? The Chronicle of Higher Education.

Antecol, Heather, Kelly Bedard, and Jenna Stearns, 2018, Who Benefits from Gender-Neutral Tenure Clock Stopping Policies?, American Economic Review 108, 2420-2441.

Bertrand, Marianne and Esther Duflo, 2016, Field Experiments on Discrimination. Prepared for the Handbook of Field Experiments.

Besser, Avi, Sari Lotem, and Virgil Zeigler-Hill, 2020, Psychological Stress and Vocal Symptoms Among University Professors in Israel: Implications of the Shift to Online Synchronous Teaching During the COVID-19 Pandemic, Journal of Voice.

Bharadwaj, P., Pai, M. M., \& Suziedelyte, A. (2017). Mental health stigma. Economics Letters, 159, 5760.

Bhagat, Sarbottam, and Dan J. Kim, 2020, Higher Education Amidst COVID-19: Challenges and Silver Lining, Information Systems Management 37, 366-371.

Bubonya, M., Cobb-Clark, D. A., \& Wooden, M. (2017). Mental health and productivity at work: Does what you do matter?. Labour economics, 46, 150-165.

Chirikov, I., Soria, K. M., Horgos, B., \& Jones-White, D. (2020). Undergraduate and graduate students' mental health during the COVID-19 pandemic.

Cui, Ruomeng and Ding, Hao and Zhu, Feng, Gender Inequality in Research Productivity During the COVID-19 Pandemic (June 9, 2020). Available at SSRN: https://ssrn.com/abstract=3623492 or http://dx.doi.org/10.2139/ssrn.3623492

Czerniewicz, Laura, Najma Agherdien, Johan Badenhorst, Dina Belluigi, Tracey Chambers, Muntuwenkosi Chili, Magriet De Villiers, Alan Felix, Daniela Gachago, Craig Gokhale, Eunice Ivala, Neil Kramm, Matete Madiba, Gitanjali Mistri, Emmanuel Mgqwashu, Nicola Pallitt, Paul Prinsloo, Kelly Solomon, Sonja Strydom, Mike Swanepoel, Faiq Waghid, and Gerrit Wissing, 2020, A Wake-Up Call: Equity, Inequality and Covid-19 Emergency Remote Teaching and Learning, Postdigital Science and Education 2, 946-967.

Das, Madhushree and Bhuyan, Chandan and Sultana, Syeda Fahima Shahnaz, COVID-19 PandemicInduced Teaching-Learning Experiences: Some Realities from Assam (India) (October 7, 2020). International Journal of Innovation, Creativity and Change 2020, Available at SSRN: https://ssrn.com/abstract=3707078.

Deryungina, Tatyana, Olga Shurchkov, and Jenna E. Stearns, 2021, Covid-19 Disruptions Disproporationately Affect Female Academics. NEBR working paper 28360.

El-Alayli, A., Hansen-Brown, A.A. \& Ceynar, M., 2018, Dancing Backwards in High Heels: Female Professors Experience More Work Demands and Special Favor Requests, Particularly from Academically Entitled Students. Sex Roles 79, 136-150.

Fischer, Karin, 2019, International Students Bailed Out Colleges in the Last Recession. They Won't This Time., The Chronicle of Higher Education.

Frederickson, Megan, 2020, COVID-19's gendered impact on academic productivity, GitHub.

Frijters, P., Johnston, D. W., \& Shields, M. A. (2014). The effect of mental health on employment: evidence from Australian panel data. Health economics, 23(9), 1058-1071.

Furstenberg, François, 2020, University Leaders Are Failing, The Chronicle of Higher Education. 
Greenberg, P. E., Fournier, A. A., Sisitsky, T., Pike, C. T., \& Kessler, R. C. (2015). The economic burden of adults with major depressive disorder in the United States (2005 and 2010). The Journal of clinical psychiatry, 76(2), 155-162.

Guarino, Cassandra M, and Victor M. H. Borden, 2017, Faculty Service Loads and Gender: Are Women Taking Care of the Academic Family?, Research in Higher Education 58, 672-694.

Hanlon, Aaron, 2019, Colleges Say More Teaching Is Better. They are Wrong. The Chronical of Higher Education, February 8, 2019.

Johnson, Nicole, George Veletsianos, and Jeff Seaman, 2020, U.S. Faculty and Administrators' Experiences and Approaches in the Early Weeks of the COVID-19 Pandemic, Online Learning 24.

Jones, Mark L. and Page, Cathren and Painter-Thorne, Suzianne Desiree and Simson, Gary J., It's Alright, Ma, It's Life and Life Only: Are Colleges and Universities Legally Obligated during the Coronavirus Pandemic to Exempt High-Risk Faculty from In-Person Teaching Requirements? (September 1, 2020). Pepperdine Law Review, Vol. 48, No. 3, 2021, Available at SSRN: https://ssrn.com/abstract=3684190 or http://dx.doi.org/10.2139/ssrn.3684190.

Kezar, Adrianna, 2020, The Future of the Academic Work Force, The Chronicle of Higher Education.

Kirschenbaum, Matthew, 2020, Don't Blame Colleges for the Coming Fall Debacle, This is just what higher education looks like in a failed state, The Chronicle of Higher Education.

Kramnick, Jonathan, 2020, The Humanities After Covid-19, The Chronicle of Higher Education. Levitt,

Larry, and Gary Claxton, 2020, How Many Teachers Are at Risk of Serious Illness If Infected with Coronavirus?, Kaiser Family Foundation.

Malisch, Jessica L., Breanna N. Harris, Shanen M. Sherrer, Kristy A. Lewis, Stephanie L. Shepherd, Pumtiwitt C. Mccarthy, Jessica L. Spott, Elizabeth P. Karam, Naima Moustaid-Moussa, Jessica Mccrory Calarco, Latha Ramalingam, Amelia E. Talley, Jaclyn E. Cañas-Carrell, Karin ArdonDryer, Dana A. Weiser, Ximena E. Bernal, and Jennifer Deitloff, 2020, Opinion: In the wake of COVID-19, academia needs new solutions to ensure gender equity, Proceedings of the National Academy of Sciences 117, 15378-15381.

Marginson, Simon, 2020, The relentless price of high individualism in the pandemic, Higher Education Research \& Development 39, 1392-1395.

Masri, Amira El, and Emma Sabzalieva, 2020, Dealing with disruption, rethinking recovery: Policy responses to the COVID-19 pandemic in higher education, Policy Design and Practice 3, 312-333.

McChesney, Jasper, and Jacqueline Bischel, 2020, Rep. The Aging of Tenure-Track Faculty in Higher Education: Implications for Succession and Diversity, CUPA-HR. Available from https://www.cupahr.org/surveys/research-briefs/.

Mengel, Friederike, Jan Sauermann, and Ulf Zolitz, 2019, Gender Bias in Teaching Evaluations, Journal of the European Economic Association 17(2), 535-566.

Minello, Alessandra, 2020, The pandemic and the female academic, Nature News (Nature Publishing Group).

Myers, Kyle R., Wei Yang Tham, Yian Yin, Nina Cohodes, Jerry Thursby, Marie C. Thursby, Peter Schiffer, Joseph T. Walsh, Karim R. Lakhani, and Dashun Wang, 2020, Unequal effects of the COVID-19 pandemic on scientists. Nature Human Behavior 4, 880-883 (2020).

Nash, Meredith, and Brendan Churchill, 2020, Caring during COVID-19: A gendered analysis of Australian university responses to managing remote working and caring responsibilities, Gender, Work \& Organization 27, 833-846.

Oleschuk, Merin, 2020, Gender Equity Considerations for Tenure and Promotion during COVID-19, Canadian Review of Sociology 57(3), 502-515. 
O'Meara, KerryAnn, Regina R. Kaufman, and Aaron M. Kuntz, 2003, Faculty Work in Challenging Times: Trends, Consequences \& Implications, Liberal Education 89. 4.

Perry, Andre, 2020, Experienced teachers could retire in droves by the time schools reopen, The Hechinger Report.

Pham, Hiep-Hung, and Tien-Thi-Hanh Ho, 2020, Toward a 'new normal' with e-learning in Vietnamese higher education during the post COVID-19 pandemic, Higher Education Research \& Development 39, 1327-1331.

Rome B. Moralista, Ryan Michael F. Oducado (2020). Faculty Perception toward Online Education in a State College in the Philippines during the Coronavirus Disease 19 (COVID-19) Pandemic. Universal Journal of Educational Research, 8(10), 4736 - 4742. DOI: 10.13189/ujer.2020.081044

Santos, Georgina, and Stephanie Dang Van Phu, 2019, Gender and Academic Rank in the UK, Sustainability11(11), Special Issue Economics of Education and Sustainable Development, 3171.

Sarsons, Heather, Klarita Gerxhani, Emesto Reuben, and Arthur Schram, 2021, Gender Differences in Recognition for Group Work, Journal of Political Economy, vol. 129, no. 1, 101-147.

Schiebinger, Londa, Andrea Davies Henderson, and Shannon K. Gilmartin, 2008, Dual-Career Academic Couples: What Universities Need to Know, Dual-Career Academic Couples: What Universities Need to Know | Office of the Vice Provost for Graduate Education.

Sugimoto, Cassidy R, Yong-Yeol Ahn, Elise Smith, Benoit Macaluso, and Vincent Larivière, 2019, Factors affecting sex-related reporting in medical research: a cross-disciplinary bibliometric analysis, The Lancet 393, 550-559.

Sugimoto, Cassidy R., 2020, The decline of women's research production during the coronavirus pandemic, Nature Index.

Viglione, Giuliana, 2020, Are women publishing less during the pandemic? Here's what the data say, Nature News (Nature Publishing Group).

Winslow, Sarah, 2010, Gender inequality and time allocations among academic faculty, Gender \& Sociaety 24, 769-793.

Woolston, Chris, 2020, Signs of depression and anxiety soar among US graduate students during pandemic, Nature News (Nature Publishing Group).

Yang, Rui, 2020, China's higher education during the COVID-19 pandemic: some preliminary observations, Higher Education Research \& Development 39, 1317-1321.

Zeeshan, Mahwish, Dr. Abid Ghafoor Chaudhry, and Shaheer Ellahi Khan, 2020, Pandemic Preparedness and Techno Stress among Faculty of DAIs in Covid-19, Sir Syed Journal of Education \& Social Research 3, 383-396. 


\section{Table 1. Summary Statistics: Means (Standard Deviation)}

Fem_ind, nowork_spouse, Child_0to5 (etc.), ExtendClock, Europe and United States are indicator variables. Research Productivity is effect of COVID on research on a Likert: (1) Strong Negative Effect to (5) Strong Positive Effect. Time varuables are time spent on an activity during the pandemic measured on a Likert scale: (1) much less to (5) much more. childcardinal is 0 for respondents with no children, 1 for those with children over 13, 2 for those with children between 5 and 13, and 3 for those with children under 5. Feedback, Isolation, Health, and Employer_Finances measure concerns on a Likert scale: (1) Not Concerned to (5) Very Concerned.

\begin{tabular}{|c|c|c|c|c|}
\hline VARIABLES & $\begin{array}{l}\text { All Faculty } \\
(\mathrm{N}=731)\end{array}$ & $\begin{array}{l}\text { Senior Faculty } \\
\quad(N=402)\end{array}$ & $\begin{array}{l}\text { Junior Faculty } \\
\qquad(\mathrm{N}=329)\end{array}$ & $\begin{array}{l}\text { PhD Students } \\
\qquad(\mathrm{N}=277)\end{array}$ \\
\hline \multirow[t]{2}{*}{ Research_Productivity } & 1.943 & 2.100 & 1.751 & 2.126 \\
\hline & (1.169) & (1.239) & (1.047) & (1.104) \\
\hline \multirow[t]{2}{*}{ Time_Research } & 2.427 & 2.478 & 2.365 & 2.957 \\
\hline & $(1.141)$ & $(1.154)$ & (1.124) & $(1.132)$ \\
\hline \multirow[t]{2}{*}{ Time_Teaching } & 3.714 & 3.761 & 3.657 & 2.928 \\
\hline & $(0.942)$ & $(0.928)$ & $(0.957)$ & $(0.873)$ \\
\hline \multirow[t]{2}{*}{ Time_Childcare } & 3.841 & 3.808 & 3.881 & 3.271 \\
\hline & $(0.935)$ & $(0.910)$ & $(0.963)$ & $(0.734)$ \\
\hline \multirow[t]{2}{*}{ Time_Chores } & 3.752 & 3.714 & 3.799 & 3.603 \\
\hline & $(0.778)$ & $(0.744)$ & $(0.817)$ & $(0.799)$ \\
\hline \multirow[t]{2}{*}{ Time_Leisure } & 1.929 & 1.893 & 1.973 & 2.466 \\
\hline & $(0.857)$ & $(0.833)$ & $(0.885)$ & (1.065) \\
\hline \multirow[t]{2}{*}{ Time_Sleep } & 2.713 & 2.736 & 2.684 & 3.162 \\
\hline & $(0.742)$ & $(0.688)$ & $(0.802)$ & $(0.900)$ \\
\hline \multirow[t]{2}{*}{ Female } & 0.300 & 0.271 & 0.334 & 0.455 \\
\hline & $(0.458)$ & $(0.445)$ & $(0.472)$ & $(0.499)$ \\
\hline \multirow[t]{2}{*}{ Nonwork_spouse } & 0.249 & 0.301 & 0.185 & 0.173 \\
\hline & $(0.433)$ & $(0.459)$ & $(0.389)$ & $(0.379)$ \\
\hline \multirow[t]{2}{*}{ Child_0to18 } & 0.592 & 0.624 & 0.553 & 0.199 \\
\hline & $(0.492)$ & $(0.485)$ & $(0.498)$ & $(0.400)$ \\
\hline \multirow[t]{2}{*}{ Child_0to5 } & 0.326 & 0.226 & 0.447 & 0.152 \\
\hline & $(0.469)$ & $(0.419)$ & $(0.498)$ & $(0.359)$ \\
\hline \multirow[t]{2}{*}{ Child_6to12 } & 0.302 & 0.361 & 0.231 & 0.069 \\
\hline & $(0.460)$ & $(0.481)$ & $(0.422)$ & $(0.253)$ \\
\hline \multirow[t]{2}{*}{ Child_13to18 } & 0.140 & 0.236 & 0.021 & 0.025 \\
\hline & $(0.347)$ & $(0.425)$ & $(0.145)$ & $(0.157)$ \\
\hline \multirow[t]{2}{*}{ Childcardinal } & 1.249 & 1.124 & 1.401 & 0.487 \\
\hline & (1.188) & $(1.042)$ & (1.331) & $(1.031)$ \\
\hline \multirow[t]{2}{*}{ Feedback } & 4.001 & 3.853 & 4.182 & 3.823 \\
\hline & $(0.855)$ & $(0.855)$ & $(0.821)$ & $(0.937)$ \\
\hline \multirow[t]{2}{*}{ Isolation } & 3.702 & 3.597 & 3.830 & 3.783 \\
\hline & $(1.140)$ & $(1.140)$ & (1.130) & $(1.205)$ \\
\hline \multirow[t]{2}{*}{ Health } & 3.658 & 3.455 & 3.906 & 4.170 \\
\hline & (1.118) & (1.149) & (1.027) & $(0.923)$ \\
\hline \multirow[t]{2}{*}{ ExtendClock } & 0.689 & 0.679 & 0.702 & 0.058 \\
\hline & $(0.463)$ & $(0.467)$ & $(0.458)$ & $(0.234)$ \\
\hline \multirow[t]{2}{*}{ Employer_Finances } & 3.446 & 3.505 & 3.374 & 3.437 \\
\hline & $(1.121)$ & (1.079) & (1.167) & (1.084) \\
\hline
\end{tabular}




\section{Table 2. Family Structure by Gender and Rank}

The table presents mean values by gender and faculty rank with tests for differences. Nonworking Spouse and Child_0to5 (6to12, 13to18) are indicator variables. Childcardinal is 0 for respondents with no children, 1 for those with children over 13, 2 for those with children between 5 and 13 , and 3 for those with children under 5 .

\begin{tabular}{|c|c|c|c|c|c|c|c|c|c|c|c|c|}
\hline & \multicolumn{3}{|c|}{$\begin{array}{c}\text { All Faculty } \\
(\mathrm{N}=731)\end{array}$} & \multicolumn{3}{|c|}{$\begin{array}{c}\text { Senior Faculty } \\
\quad(\mathrm{N}=402)\end{array}$} & \multicolumn{3}{|c|}{$\begin{array}{c}\text { Junior Faculty } \\
(\mathrm{N}=329)\end{array}$} & \multicolumn{3}{|c|}{$\begin{array}{l}\text { PhD Students } \\
\quad(\mathrm{N}=277)\end{array}$} \\
\hline & Men & Women & $\begin{array}{c}\text { Men - } \\
\text { Women }\end{array}$ & Men & Women & $\begin{array}{c}\text { Men - } \\
\text { Women }\end{array}$ & Men & Women & $\begin{array}{c}\text { Men - } \\
\text { Women }\end{array}$ & Men & Women & $\begin{array}{c}\text { Men - } \\
\text { Women }\end{array}$ \\
\hline NonworkingSpouse & 0.295 & 0.142 & $0.153^{* * *}$ & 0.345 & 0.183 & $0.161^{* * *}$ & 0.228 & 0.100 & $0.128 * * *$ & 0.219 & 0.119 & $0.099 * *$ \\
\hline Child_0to5 & 0.334 & 0.306 & 0.028 & 0.222 & 0.239 & -0.017 & 0.484 & 0.373 & $0.111^{*}$ & 0.159 & 0.143 & 0.016 \\
\hline Child_6to12 & 0.301 & 0.306 & -0.005 & 0.324 & 0.459 & $-0.134^{* *}$ & 0.269 & 0.155 & $0.115^{* *}$ & 0.060 & 0.079 & -0.020 \\
\hline Child_13to18 & 0.141 & 0.137 & 0.004 & 0.229 & 0.257 & -0.028 & 0.023 & 0.018 & 0.005 & 0.026 & 0.024 & 0.003 \\
\hline Child_0to18 & 0.605 & 0.562 & 0.044 & 0.608 & 0.670 & -0.062 & 0.603 & 0.455 & $0.148 * *$ & 0.199 & 0.198 & 0.000 \\
\hline Childcardinal & 1.275 & 1.187 & 0.088 & 1.102 & 1.183 & -0.081 & 1.507 & 1.191 & $0.316^{* *}$ & 0.490 & 0.484 & 0.006 \\
\hline
\end{tabular}




\section{Table 3. COVID Time Effects and Family Structure}

The sample includes research faculty in tenure-track university positions. The dependent variable is time spent on an activity during the pandemic measured on a Likert scale that ranges from (1) much less to (5) much more. The independent variables include a gender indicator, a nonworking spouse indicator, and cardinal child variable. The child variable is 0 for respondents with no children, 1 for those with children over 13, 2 for those with children between 5 and 13, and 3 for those with children under 5. Models are estimated as ordered logistic regressions in a seemingly unrelated regression framework.

\begin{tabular}{lcccccc}
\hline & $\begin{array}{c}(1) \\
\text { Time_ } \\
\text { Research }\end{array}$ & $\begin{array}{c}(2) \\
\text { Time_ } \\
\text { Teaching }\end{array}$ & $\begin{array}{c}(3) \\
\text { Time_ } \\
\text { Chores }\end{array}$ & $\begin{array}{c}(4) \\
\text { Time_ } \\
\text { Childcare }\end{array}$ & $\begin{array}{c}(5) \\
\text { Time_ } \\
\text { Leisure }\end{array}$ & $\begin{array}{c}(6) \\
\text { Time_ } \\
\text { Sleep }\end{array}$ \\
\hline \multirow{2}{*}{ Female } & & & & & & \\
& $-0.420^{* *}$ & $0.499^{* *}$ & -0.0337 & -0.308 & 0.0572 & -0.0544 \\
Nonwork_spouse & {$[0.199]$} & {$[0.221]$} & {$[0.211]$} & {$[0.213]$} & {$[0.202]$} & {$[0.236]$} \\
& 0.124 & $0.262^{*}$ & -0.125 & $-0.360^{*}$ & -0.210 & -0.0787 \\
Childcardinal & {$[0.165]$} & {$[0.158]$} & {$[0.153]$} & {$[0.189]$} & {$[0.159]$} & {$[0.157]$} \\
Female*Childcardinal & $-0.596^{* * *}$ & -0.00674 & $0.427^{* * *}$ & $1.631^{* * *}$ & $-0.272^{* * *}$ & $-0.539^{* * *}$ \\
& {$[0.0740]$} & {$[0.0680]$} & {$[0.0736]$} & {$[0.112]$} & {$[0.0697]$} & {$[0.0740]$} \\
& 0.0320 & -0.0916 & 0.173 & $0.442^{* *}$ & $-0.282^{* *}$ & -0.141 \\
Observations & {$[0.121]$} & {$[0.132]$} & {$[0.133]$} & {$[0.203]$} & {$[0.136]$} & {$[0.140]$} \\
\hline
\end{tabular}

Robust standard errors in brackets

$* * * \mathrm{p}<0.01, * * \mathrm{p}<0.05, * \mathrm{p}<0.1$ 


\section{Table 4. COVID Research Effects}

The sample includes research faculty in tenure-track university positions. The dependent variable is research productivity during the pandemic measured on a Likert scale ranging from (1) Strong Negative Effect to (5) Strong Positive Effect. The independent variables include indicators for gender, nonworking spouse, and a cardinal child variable. The independent time variables measure time spent on an activity during the pandemic measured on a Likert scale that ranges from (1) much less to (5) much more. Feedback, Isolation, and Health measure concern about timely feedback on research, isolation, and physical/mental health on a Likert scale ranging form (1) Not Concerned to (5) Very Concerned. Models are estimated as ordered logistic regressions.

\begin{tabular}{|c|c|c|c|c|}
\hline VARIABLES & $\begin{array}{c}\text { (1) } \\
\text { Research_- } \\
\text { Productivity }\end{array}$ & $\begin{array}{c}\text { (2) } \\
\text { Research_- } \\
\text { Productivity }\end{array}$ & $\begin{array}{c}\text { (3) } \\
\text { Research_- } \\
\text { Productivity }\end{array}$ & $\begin{array}{c}\text { (4) } \\
\text { Research_ } \\
\text { Productivity }\end{array}$ \\
\hline Female & $\begin{array}{c}-0.650 * * * \\
{[0.213]}\end{array}$ & $\begin{array}{c}-0.794 * * * \\
{[0.217]}\end{array}$ & $\begin{array}{c}-0.718 * * * \\
{[0.219]}\end{array}$ & $\begin{array}{c}-0.514^{* *} \\
{[0.223]}\end{array}$ \\
\hline Nonwork_spouse & $\begin{array}{c}0.305^{*} \\
{[0.163]}\end{array}$ & $\begin{array}{c}0.208 \\
{[0.167]}\end{array}$ & $\begin{array}{c}0.277 \\
{[0.168]}\end{array}$ & $\begin{array}{c}0.197 \\
{[0.171]}\end{array}$ \\
\hline Childcardinal & $\begin{array}{c}-0.550 * * * \\
{[0.0740]}\end{array}$ & $\begin{array}{r}-0.00796 \\
{[0.0931]}\end{array}$ & $\begin{array}{c}-0.0617 \\
{[0.0940]}\end{array}$ & $\begin{array}{c}-0.117 \\
{[0.0989]}\end{array}$ \\
\hline Female*childcardinal & $\begin{array}{c}0.192 \\
{[0.134]}\end{array}$ & $\begin{array}{c}0.378 * * * \\
{[0.135]}\end{array}$ & $\begin{array}{c}0.378 * * * \\
{[0.138]}\end{array}$ & $\begin{array}{c}0.382 * * * \\
{[0.142]}\end{array}$ \\
\hline Time_Childcare & & $\begin{array}{c}-1.000 * * * \\
{[0.126]}\end{array}$ & $\begin{array}{c}-0.951 * * * \\
{[0.128]}\end{array}$ & $\begin{array}{c}-0.920 * * * \\
{[0.134]}\end{array}$ \\
\hline Time_Chores & & $\begin{array}{c}-0.404^{* * *} \\
{[0.108]}\end{array}$ & $\begin{array}{c}-0.456 * * * \\
{[0.110]}\end{array}$ & $\begin{array}{c}-0.319 * * * \\
{[0.113]}\end{array}$ \\
\hline Time_Teaching & & & $\begin{array}{c}-0.600 * * * \\
{[0.0820]}\end{array}$ & $\begin{array}{c}-0.514 * * * \\
{[0.0840]}\end{array}$ \\
\hline Feedback & & & & $\begin{array}{c}-0.577 * * * \\
{[0.0979]}\end{array}$ \\
\hline Isolation & & & & $\begin{array}{c}-0.128^{*} \\
{[0.0748]}\end{array}$ \\
\hline Health & & & & $\begin{array}{c}-0.385^{* * *} \\
{[0.0760]}\end{array}$ \\
\hline Observations & 731 & 731 & 731 & 730 \\
\hline
\end{tabular}

Standard errors in brackets $* * * \mathrm{p}<0.01,{ }^{* *} \mathrm{p}<0.05, * \mathrm{p}<0.1$ 
Table 5. COVID Research Effects by Rank (Senior Faculty, Junior Faculty, or Student)

The subsamples includes research tenured faculty in university positions (senior faculty), untenured faculty in university positions (junior faculty), and students. The dependent variable is research productivity during the pandemic measured on a Likert scale ranging from (1) Strong Negative Effect to (5) Strong Positive Effect. The independent variables include indicators for gender, nonworking spouse, and a cardinal child variable. The independent time variables measure time spent on an activity during the pandemic measured on a Likert scale that ranges from (1) much less to (5) much more. Feedback, Isolation, and Health measure concern about timely feedback on research, isolation, and physical/mental health on a Likert scale ranging form (1) Not Concerned to (5) Very Concerned. Models are estimated as ordered logistic regressions.

\begin{tabular}{|c|c|c|c|c|c|c|}
\hline & \multicolumn{2}{|c|}{ Senior Faculty } & \multicolumn{2}{|c|}{ Junior Faculty } & \multicolumn{2}{|c|}{ Students } \\
\hline VARIABLES & $\begin{array}{c}(1) \\
\text { Research_- } \\
\text { Productivity }\end{array}$ & $\begin{array}{c}(2) \\
\text { Research_- } \\
\text { Productivity }\end{array}$ & $\begin{array}{c}\text { (3) } \\
\text { Research_- } \\
\text { Productivity }\end{array}$ & $\begin{array}{c}\text { (4) } \\
\text { Research_- } \\
\text { Productivity }\end{array}$ & $\begin{array}{c}5) \\
\text { Research_- } \\
\text { Productivity } \\
\end{array}$ & $\begin{array}{c}6) \\
\text { Research_- } \\
\text { Productivity } \\
\end{array}$ \\
\hline Female & $\begin{array}{c}-0.733 * * \\
{[0.311]}\end{array}$ & $\begin{array}{c}-0.471 \\
{[0.333]}\end{array}$ & $\begin{array}{c}-0.399 \\
{[0.305]}\end{array}$ & $\begin{array}{c}-0.584 * \\
{[0.321]}\end{array}$ & $\begin{array}{c}-0.0666 \\
{[0.243]}\end{array}$ & $\begin{array}{c}0.0505 \\
{[0.250]}\end{array}$ \\
\hline Nonwork_spouse & $\begin{array}{c}0.0473 \\
{[0.204]}\end{array}$ & $\begin{array}{l}-0.0300 \\
{[0.214]}\end{array}$ & $\begin{array}{c}0.538^{*} \\
{[0.283]}\end{array}$ & $\begin{array}{c}0.491 \\
{[0.301]}\end{array}$ & $\begin{array}{c}-0.228 \\
{[0.299]}\end{array}$ & $\begin{array}{c}-0.0772 \\
{[0.310]}\end{array}$ \\
\hline Childcardinal & $\begin{array}{c}-0.618^{* * *} \\
{[0.109]}\end{array}$ & $\begin{array}{c}-0.183 \\
{[0.139]}\end{array}$ & $\begin{array}{c}-0.474 * * * \\
{[0.106]}\end{array}$ & $\begin{array}{c}-0.0144 \\
{[0.146]}\end{array}$ & $\begin{array}{c}-0.148 \\
{[0.154]}\end{array}$ & $\begin{array}{c}-0.0559 \\
{[0.186]}\end{array}$ \\
\hline Female*childcardinal & $\begin{array}{c}0.142 \\
{[0.214]}\end{array}$ & $\begin{array}{c}0.494 * * \\
{[0.234]}\end{array}$ & $\begin{array}{c}0.175 \\
{[0.176]}\end{array}$ & $\begin{array}{c}0.341^{*} \\
{[0.188]}\end{array}$ & $\begin{array}{c}-0.326 \\
{[0.233]}\end{array}$ & $\begin{array}{c}-0.239 \\
{[0.246]}\end{array}$ \\
\hline Time_Childcare & & $\begin{array}{c}-0.875^{* * *} \\
{[0.178]}\end{array}$ & & $\begin{array}{c}-1.064 * * * \\
{[0.209]}\end{array}$ & & $\begin{array}{c}-0.215 \\
{[0.220]}\end{array}$ \\
\hline Time_Chores & & $\begin{array}{c}-0.332 * * \\
{[0.160]}\end{array}$ & & $\begin{array}{c}-0.319 * * \\
{[0.162]}\end{array}$ & & $\begin{array}{c}-0.293^{*} \\
{[0.155]}\end{array}$ \\
\hline Time_Teaching & & $\begin{array}{c}-0.608^{* * *} \\
{[0.114]}\end{array}$ & & $\begin{array}{c}-0.441 * * * \\
{[0.129]}\end{array}$ & & $\begin{array}{c}-0.193 \\
{[0.140]}\end{array}$ \\
\hline Feedback & & $\begin{array}{c}-0.587 * * * \\
{[0.134]}\end{array}$ & & $\begin{array}{c}-0.548 * * * \\
{[0.151]}\end{array}$ & & $\begin{array}{c}-0.522 * * * \\
{[0.134]}\end{array}$ \\
\hline Isolation & & $\begin{array}{c}-0.106 \\
{[0.100]}\end{array}$ & & $\begin{array}{c}-0.150 \\
{[0.115]}\end{array}$ & & $\begin{array}{c}-0.272 * * * \\
{[0.102]}\end{array}$ \\
\hline Health & & $\begin{array}{c}-0.427^{* * *} \\
{[0.101]}\end{array}$ & & $\begin{array}{c}-0.267 * * \\
{[0.122]}\end{array}$ & & $\begin{array}{c}-0.392 * * * \\
{[0.130]}\end{array}$ \\
\hline Observations & 402 & 401 & 329 & 329 & 277 & 277 \\
\hline
\end{tabular}




\section{Table 6. Mechanism Intensity by Rank and Gender}

The dependent variables are Feedback, Isolation, Health, and childcardinal. Odd columns use the sample of tenure-track faculty with independent indicator variables for gender and junior rank. Even columns use the sample of tenure-track faculty plus students and add indicators for student and its interaction with gender. Models are estimated as ordered logit regressions.

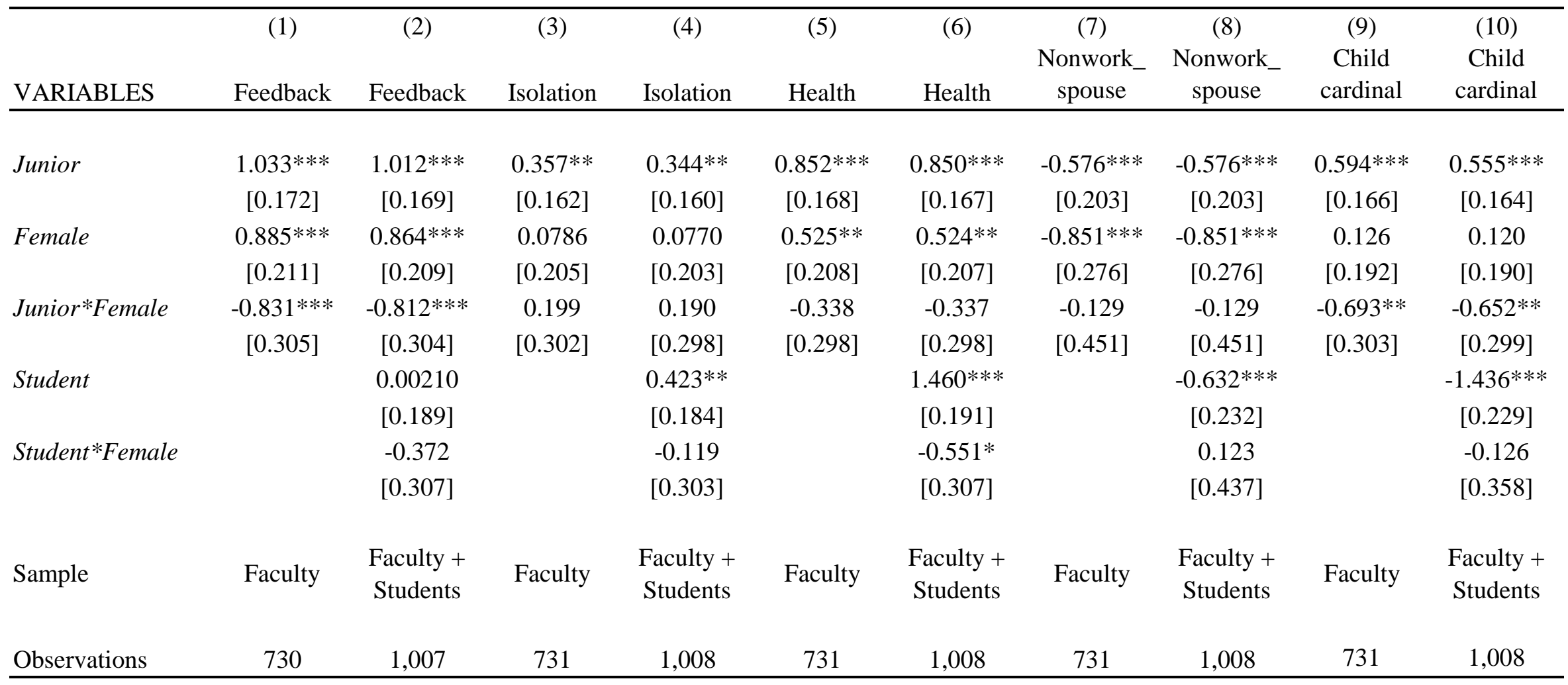

Standard errors in brackets

$* * * \mathrm{p}<0.01, * * \mathrm{p}<0.05, * \mathrm{p}<0.1$ 


\section{Table 7. Institution Finances and Policy Responses}

In Panel A, the sample is all tenure-track university faculty and Employer_Finances measure concerns on a Likert scale: (1) Not Concerned to (5) Very Concerned. In Panel B, ExtendClock is an indicator that takes a value of one when respondent indicates institution had an automatic or optional clock extension in response to the pandemic.

\begin{tabular}{|c|c|c|c|c|c|c|}
\hline VARIABLES & $\begin{array}{c}\text { (1) } \\
\text { Research_- } \\
\text { Productivity }\end{array}$ & $\begin{array}{c}(2) \\
\text { Time_- } \\
\text { Research }\end{array}$ & $\begin{array}{c}(3) \\
\text { Time_- } \\
\text { Teaching }\end{array}$ & Feedback & Isolation & Health \\
\hline \multicolumn{7}{|c|}{ Panel A. Employer Finances } \\
\hline$\overline{\text { Employer_Finances }}$ & $\begin{array}{c}-0.307 * * * \\
{[0.0621]}\end{array}$ & $\begin{array}{c}-0.216 * * * \\
{[0.0610]}\end{array}$ & $\begin{array}{c}0.272 * * * \\
{[0.0606]}\end{array}$ & $\begin{array}{c}0.282 * * * \\
{[0.0632]}\end{array}$ & $\begin{array}{c}0.313^{* * *} \\
{[0.0630]}\end{array}$ & $\begin{array}{c}0.378 * * * \\
{[0.0641]}\end{array}$ \\
\hline Observations & 731 & 731 & 731 & 730 & 731 & 731 \\
\hline \multicolumn{7}{|c|}{ Panel B. Clock Extensions } \\
\hline ExtendClock & $\begin{array}{c}-0.388 * \\
{[0.232]}\end{array}$ & $\begin{array}{c}-0.319 \\
{[0.221]}\end{array}$ & $\begin{array}{c}-0.376^{*} \\
{[0.220]}\end{array}$ & $\begin{array}{c}0.325 \\
{[0.228]}\end{array}$ & $\begin{array}{c}0.269 \\
{[0.221]}\end{array}$ & $\begin{array}{c}0.286 \\
{[0.219]}\end{array}$ \\
\hline Observations & 329 & 329 & 329 & 329 & 329 & 329 \\
\hline
\end{tabular}

Standard errors in brackets

$* * * \mathrm{p}<0.01, * * \mathrm{p}<0.05, * \mathrm{p}<0.1$ 

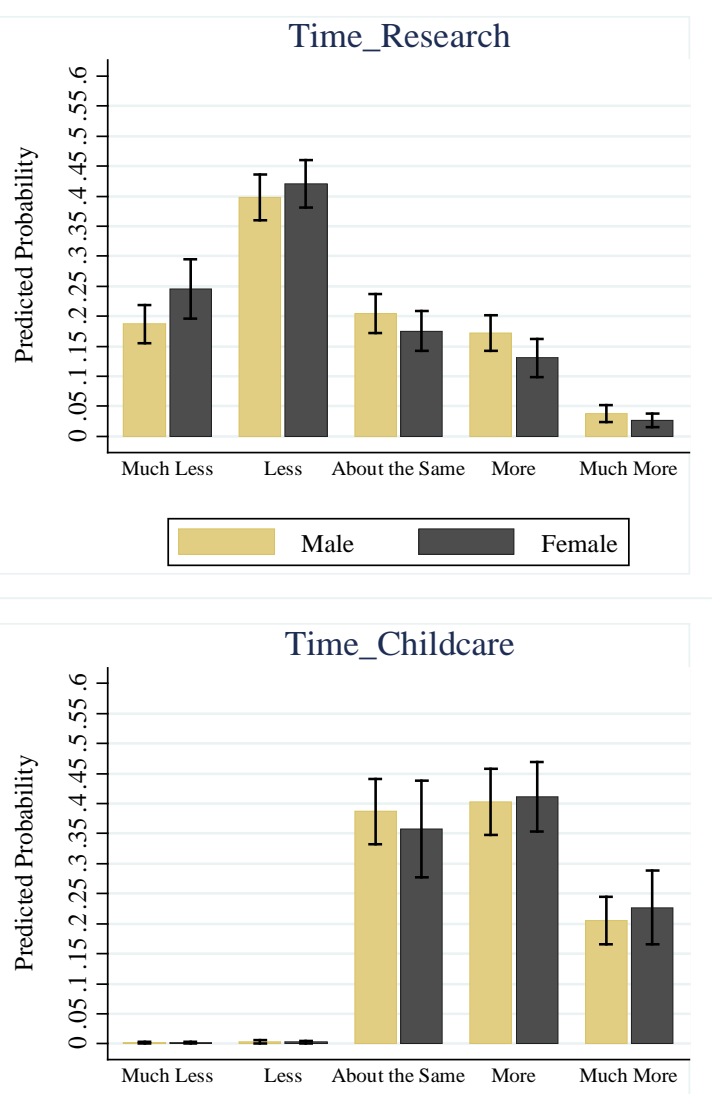

\begin{tabular}{|ll|}
\hline Male & Female \\
\hline
\end{tabular}
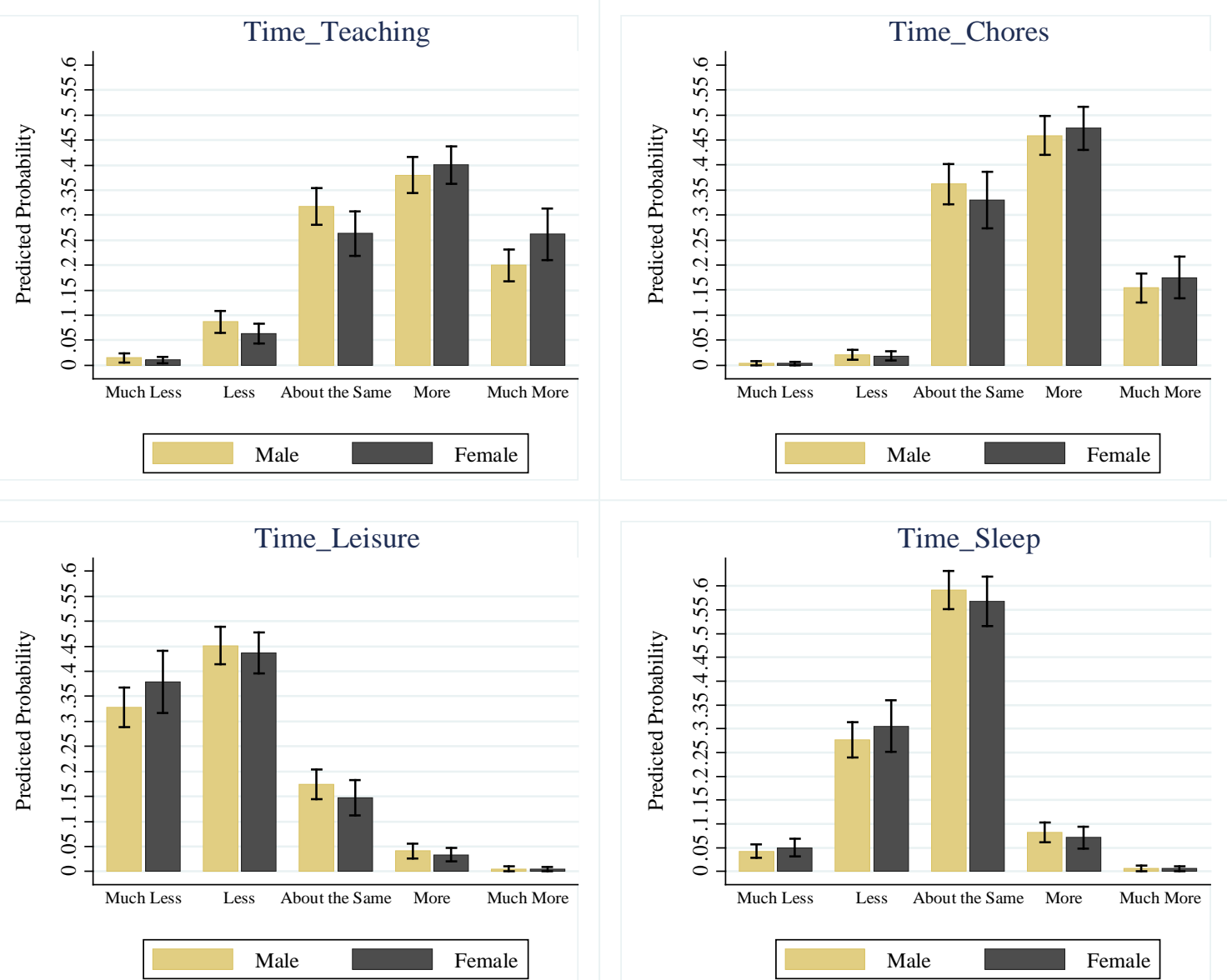

\section{Figure 1: Predicted Probabilites of Time Usage with the Marginal Effects of Gender}

Plotted in each of the figures above is the marginal effect of gender on the predicted probability of a time-use level ("much less", "less", "about the same", "more", and "much more") from each of the respective estimation of columns (1) - (6) of Table 3. In Table 3, the dependent variable for a column is a timeuse variable -- research, teaching, chores, childcare, leisure, or sleep. The estimation is an ordered logit. Independent variables are non-working spouse, the cardinal child variable, the female indicator, and an interaction between female and the cardinal child variable. We take the marginal effect on the predicted probabily of a response bucket by gender, at the mean of the other independent variables. The confidence bands shown are at the $95 \%$ level. 

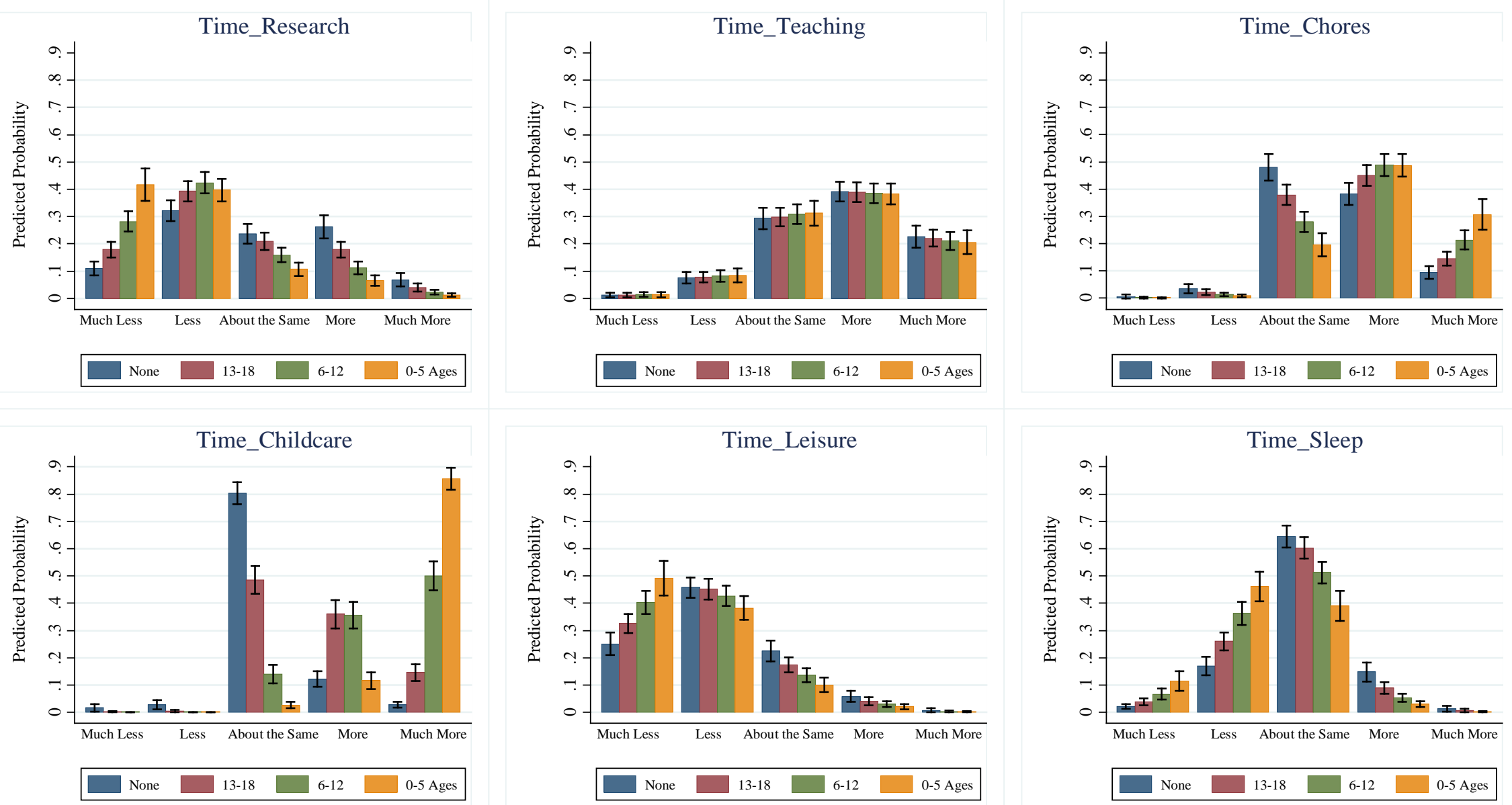

Figure 2: Predicted Probabilites of Time Usage with the Marginal Effects of Children

Plotted in each of the figures above is the marginal effect of the levels of the cardinal child variable on the predicted probability of a time-use level ("much less", "less", "about the same", "more", and "much more") from each of the respective estimation of columns (1) - (6) of Table 3. The levels of the child variable -- the ages of children, if any -- are given in the legend. In Table 3, the dependent variable for a column is a time use variable -- research, teaching, chores, childcare, leisure, or sleep. The estimation is an ordered logit. Independent variables are non-working spouse, the cardinal child variable, the female indicator, and an interaction between female and the cardinal child variable. We take the marginal effect on the predicted probabily of a response bucket by the cardinal child variable, at the mean of the other independent variables. The confidence bands shown are at the $95 \%$ level. 

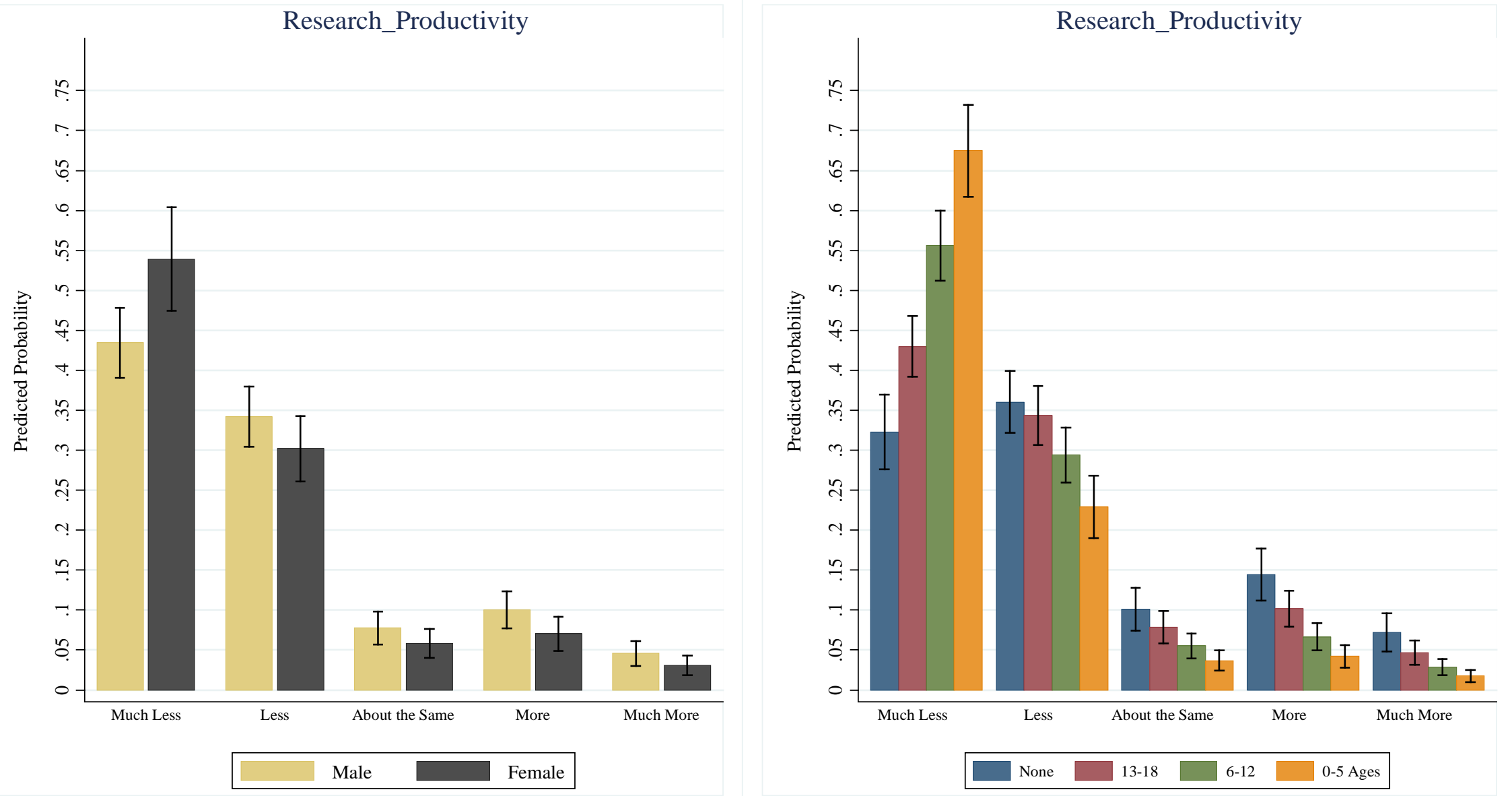

\section{Figure 3: Predicted Probabilites of Research Productivity with Marginal Effects of Gender and Chlidren}

Plotted in each of the figures above is the marginal effect of gender on the predicted probability of Research Productivity response being in one if the five choices ("much less", "less", "about the same", "more", and "much more"), from Table 4, column 1 . The estimation is an ordered logit of answers to the Research Productivity level. Independent variables are non-working spouse, the cardinal child variable, the female indicator, and an interaction between female and the cardinal child variable. For the left figure, we take the marginal effect on the predicted probabily of a response bucket by gender, at the mean of the other independent variables. For the right figure, we take the marginal effect on the predicted probabily of a response bucket by the cardinal child variable, at the mean of the other independent variables.The confidence bands shown are at the $95 \%$ level. 

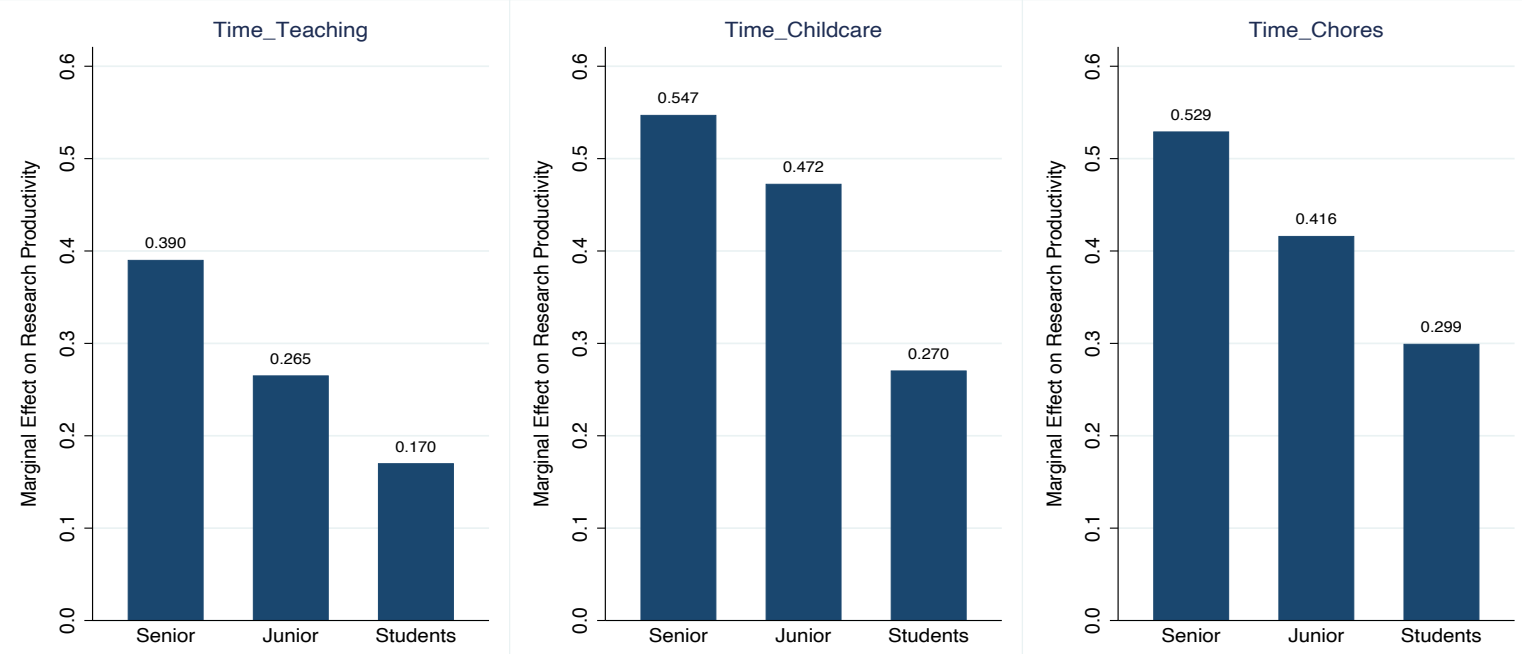

Marginal Effect ('Much More Time' - 'No Change in Time')

Panel B. Marginal Effect of Production Mechanisms
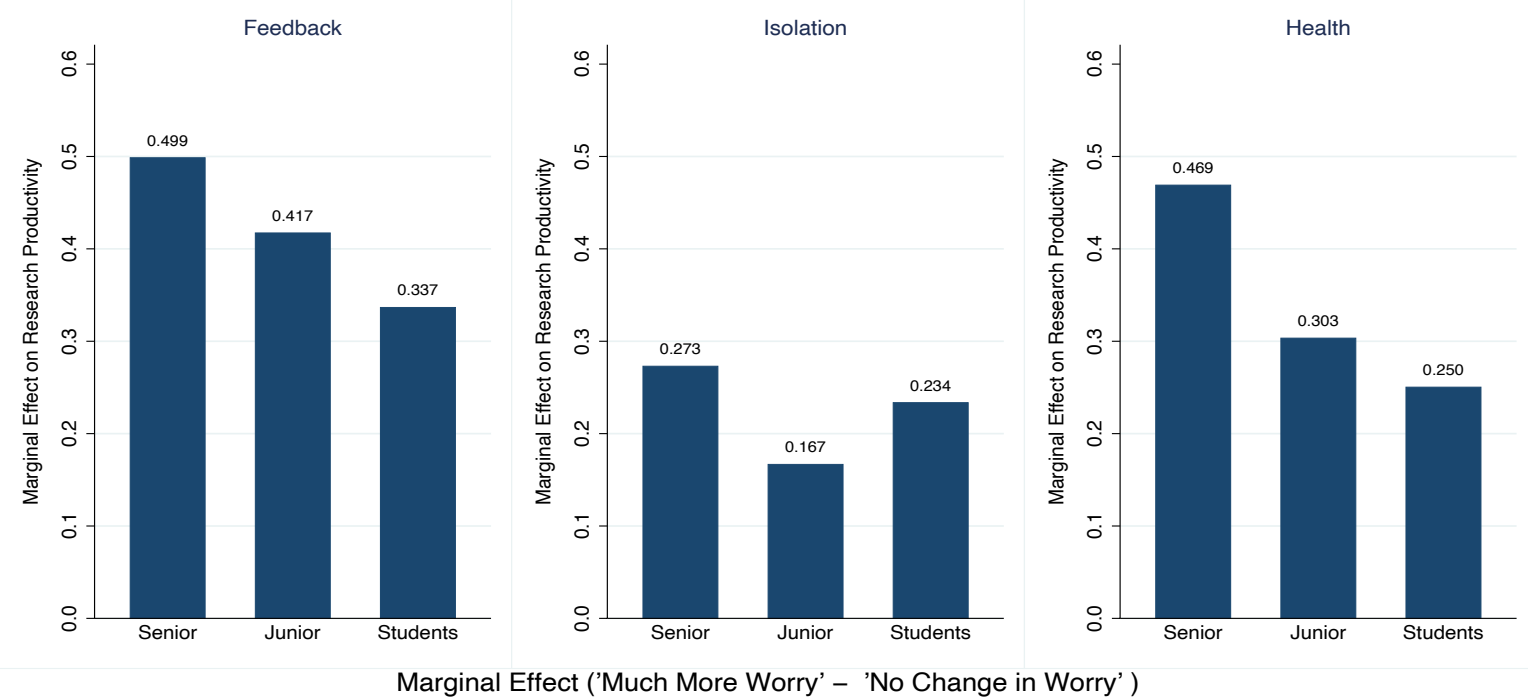

Figure 4. Marginal Effects of Time and Production Mechanisms on Most Negative Research Outcome

The figure presents the marginal effect of reporting the most extreme negative effect on research productivity (a score of 1 on the 5-point Likert scale) associated with moving from "no change" (or a score of 3 on the 5-point Likert scale) to "much more" (a score of 5) for a particular mechanism while all other covariates are assessed at the sample mean. Marginal effects are estimated for senior, junior, and students using models 2, 4, and 6 of Table 5 (respectively). Panel A summarizes time allocation mechanisms (teaching, childcare, and chores). Panel B summarizes production mechanisms (concerns about feedback, isolation, and health). 

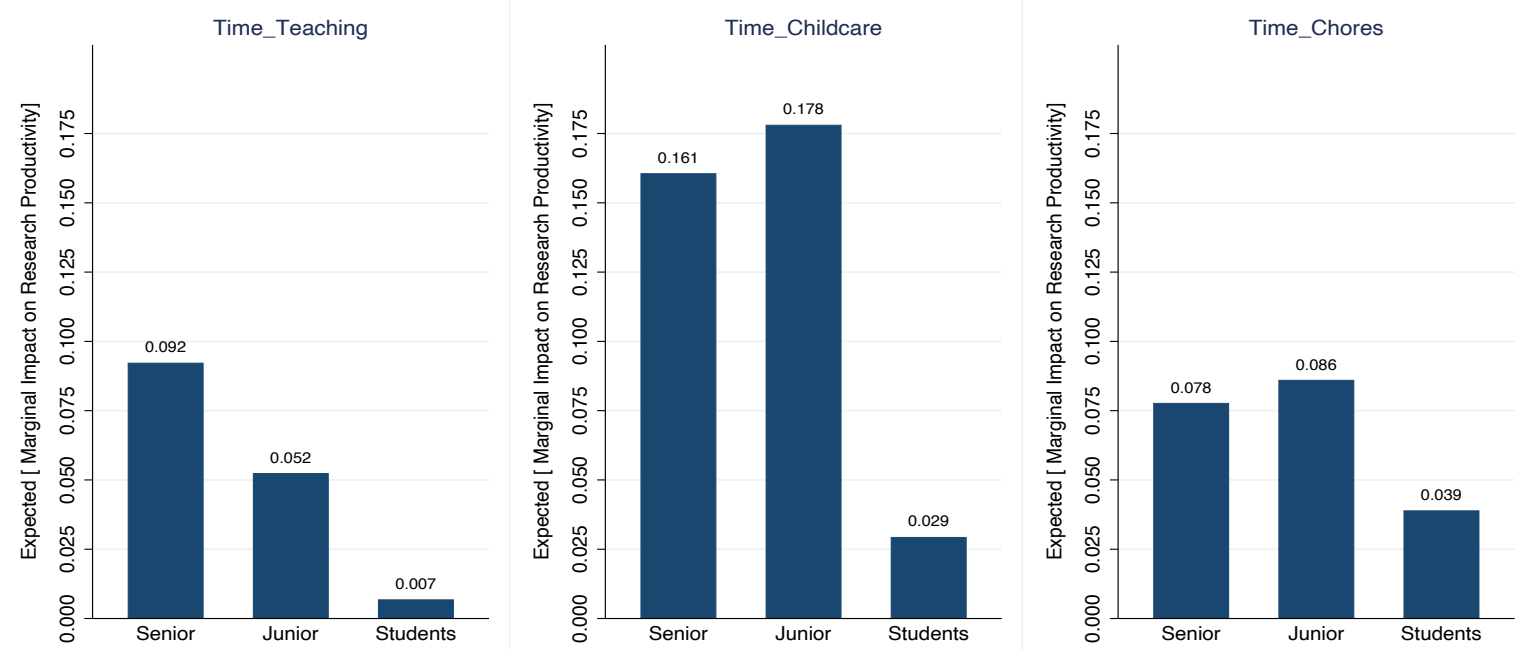

Marginal Effect ('Much More Time' - 'No Change in Time' ) X Pr('Much More Time')

Panel B. Expected Marginal Effect of Production Mechanisms
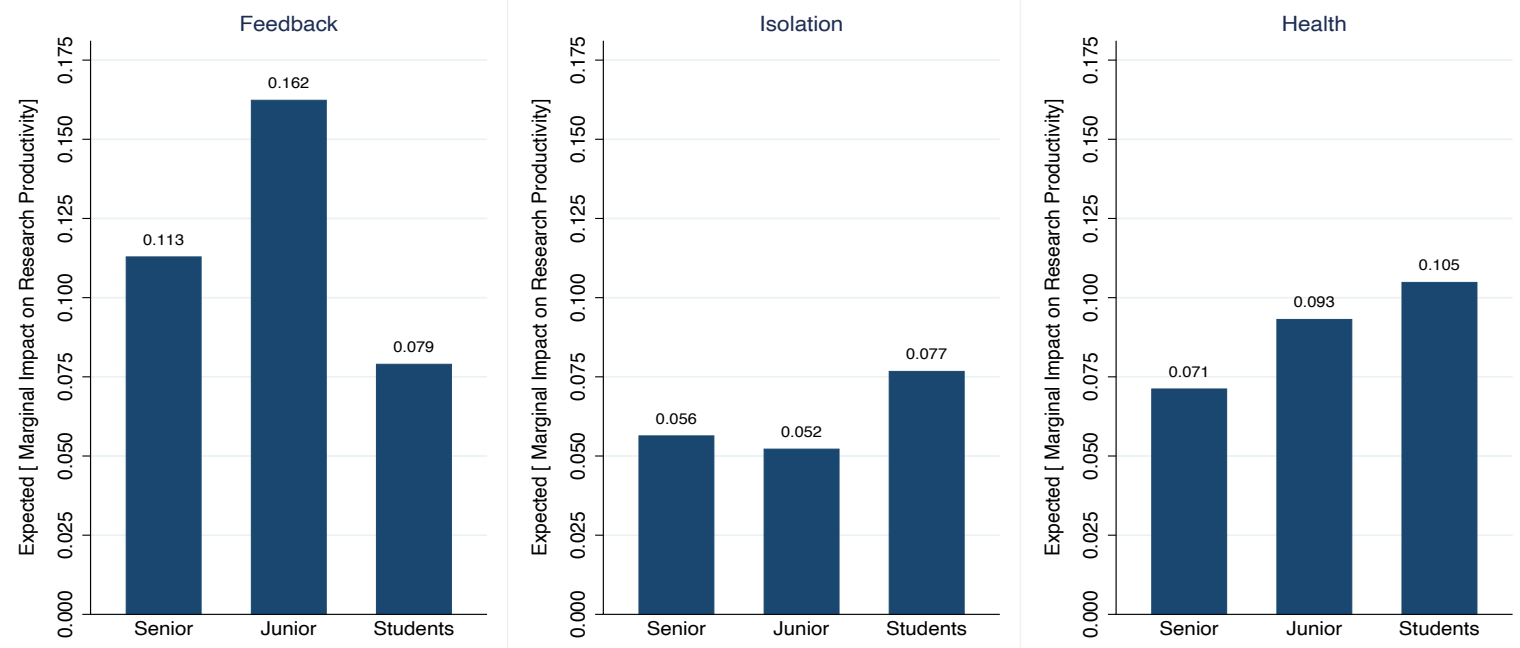

Marginal Effect ('Much More Worry' - 'No Change in Worry' ) X Pr('Much More Worry')

Figure 5. Expected Marginal Effects of Time and Production Mechanisms on Most Negative Research Outcome

The figure presents the expected marginal effect for a member of group (senior, junior, or student) reporting the most extreme effect on research productivity that can be traced to a particular mechanism. The expected marginal effect is calculated as the marginal effect (reported in Table 4) multiplied by the probability that the group (senior, junior, or student) reports "much more" (a score of 5 on the 5-point Likert scale) for a particular mechanism. Panel A summarizes time allocation mechanisms (teaching, childcare, and chores). Panel B summarizes production mechanisms (concerns about feedback, isolation, and health). 

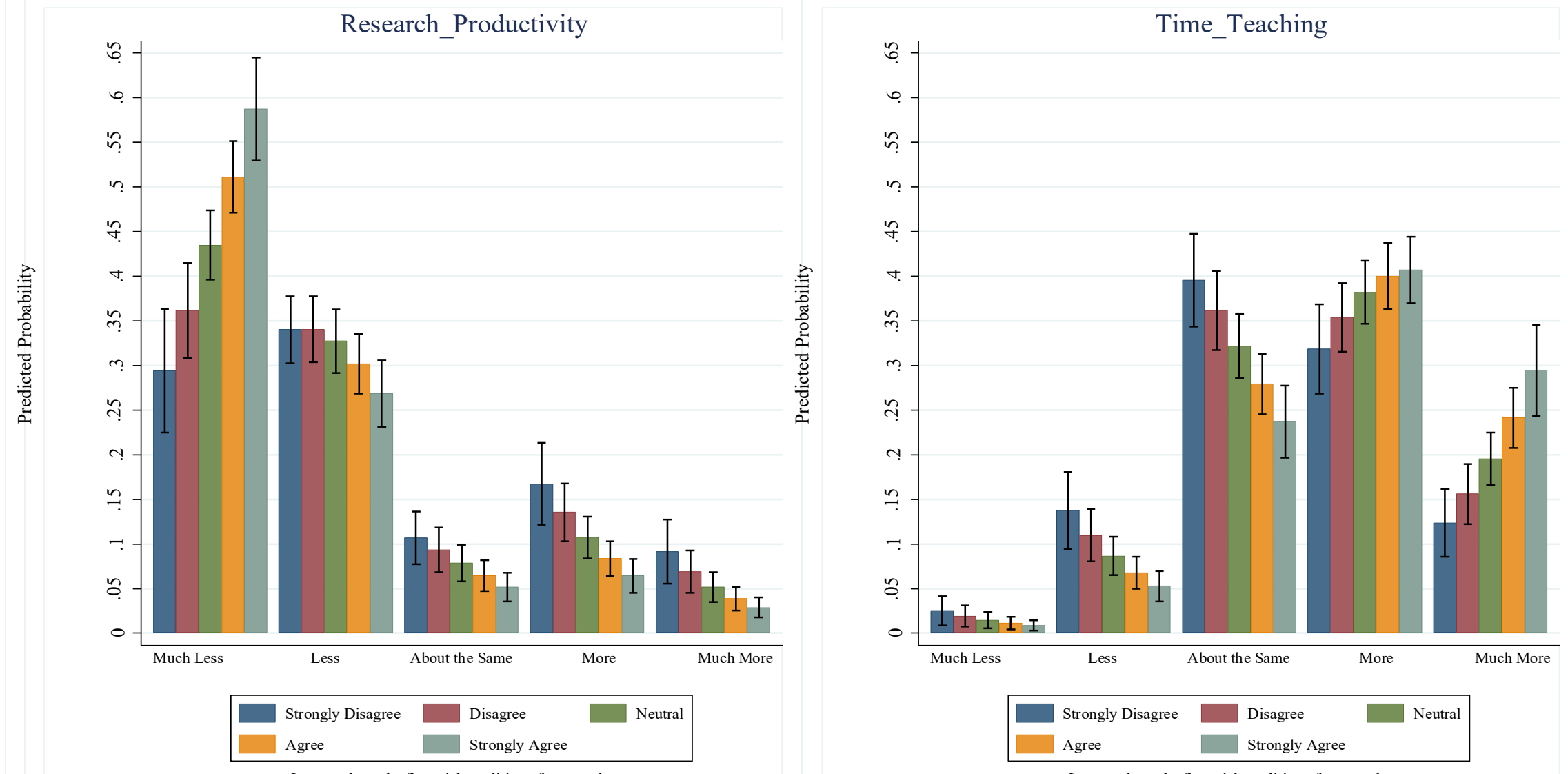

I worry about the financial condition of my employer

I worry about the financial condition of my employer

\section{Figure 6: Predicted Probabilites of Research Productity and Teaching with Marginal Effects of the Financial Condition of Employer}

Plotted in each of the figures above is the marginal effect of gender on the predicted probability of Research Productivity response being in one if the five choices ("much less", "less", "about the same", "more", and "much more"), from Table 4, column 1. The estimation is an ordered logit of answers to the Research Productivity level. Independent variables are non-working spouse, the cardinal child variable, the female indicator, and an interaction between female and the cardinal child variable. For the left figure, we take the marginal effect on the predicted probabily of a response bucket by gender, at the mean of the other independent variables. For the right figure, we take the marginal effect on the predicted probabily of a response bucket by the cardinal child variable, at the mean of the other independent variables. The confidence bands shown are at the $95 \%$ level. 